\title{
Imaging diagnosis and the role of endovascular embolization treatment for vascular intraspinal tumors
}

\author{
Marlise P. dos Santos, MD, MSc, FRCPC, ${ }^{1}$ Jingwen Zhang, MD, MSc, PhD, ${ }^{1,2}$ Diana Ghinda, MD, ${ }^{3}$ \\ Rafael Glikstein, MD, ${ }^{1}$ Ronit Agid, MD, FRCPC, ${ }^{4}$ Georges Rodesch, MD, PhD, ${ }^{5}$ \\ Donatella Tampieri, MD, FRCPC, ${ }^{6}$ and Karel G. terBrugge, MD, FRCPC ${ }^{4}$
}

\begin{abstract}
'Department of Medical Imaging, The Ottawa Hospital, University of Ottawa, and ${ }^{3}$ Department of Surgery, Division of Neurosurgery, University of Ottawa; ${ }^{4}$ Department of Medical Imaging, University Health Network, University of Toronto, Ontario; ${ }^{6}$ Montreal Neurological Institute, Departments of Radiology, Neurology and Neurosurgery, McGill University, Montreal, Quebec, Canada; ' Department of Radiology, First Affiliated Hospital, Dalian Medical University, Dalian, Liaoning, China; and ${ }^{5}$ Service de Neuroradiologie Diagnostique et Thérapeutique, Hôpital Foch, Suresnes, France
\end{abstract}

\begin{abstract}
Intraspinal tumors comprise a large spectrum of neoplasms, including hemangioblastomas, paragangliomas, and meningiomas. These tumors have several common characteristic imaging features, such as highly vascular mass appearance in angiography, hypointense rim and serpentine flow voids in MRI, and intense enhancement after intravenous contrast administration. Due to their rich vascularity, these tumors represent a special challenge for surgical treatment. More recently, the surgical treatment of intraspinal vascular tumors has benefited from the combination of endovascular techniques used to better delineate these lesions and to promote preoperative reduction of volume and tissue blood flow. Endovascular embolization has been proven to be a safe procedure that facilitates the resection of these tumors; hence, it has been proposed as part of the standard of care in their management.
\end{abstract}

http://thejns.org/doi/abs/10.3171/2015.5.FOCUS1514

KEY WORDS vascular; spinal; meningioma; paraganglioma; hemangioblastoma; embolization; surgery; diagnosis

$\mathrm{S}$ PINAL tumors comprise a wide range of neoplasms, which can be compartmentally grouped as intramedullary, intradural/extramedullary, and extradural. Hypervascular intraspinal tumors, including hemangioblastoma, paraganglioma, and meningioma, have specific imaging characteristics related to their rich blood supply. The clinical presentation of these tumors is determined in part by their location; however, in most instances, pain is the predominant presenting symptom. These tumors can be particularly challenging to resect due to the risk of hemorrhage and edema and their subsequent complications.

Endovascular embolization has been chosen as a standard approach in some institutions to facilitate the management of patients with vascular spinal tumors by reducing the surgical complications and improving the clinical outcome. The purpose of this article is to describe the most common imaging modalities used to evaluate the vascular intraspinal tumors and to review their imaging characteristics and the indications and options for endovascular embolization treatment.

\section{Imaging Techniques \\ Plain Film Radiography}

Plain film radiographs of long-standing vascular intraspinal tumors may demonstrate widening of the interpedicular distance and enlargement of the spinal canal and neural foramina, with scalloping of the vertebral bodies, pedicle erosion, and thinning of the lamina. Widening of the spinal canal occurs in children and young adults with myxopapillary ependymoma located in the conus medullaris and filum terminale. In adults, abnormal findings include straightening of the spine. Progressive scoliosis should alert the clinician to the possibility of an underlying intramedullary lesion. ${ }^{22}$

\section{Computed Tomography}

Computed tomography (CT) may show widening of the spinal canal. Plain CT should not be chosen as a screening modality for intraspinal lesions because the visualization of the canal content is limited by the surrounding bone.

ABBREVIATIONS CSF = cerebrospinal fluid; $C T=$ computed tomography; $C T A=C T$ angiography; $D S A=$ digital subtraction angiography; $D T I=$ diffusion tensor tractography; MIP = maximum intensity projection; $M R=$ magnetic resonance; $M R A=M R$ angiography; MRI = MR imaging; MRS $=$ MR spectroscopy; NBCA $=N$-butyl cyanoacrylate; PVA = polyvinyl alcohol; VHL = von Hippel-Lindau.

SUBMITTED January 9, 2015. ACCEPTED May 21, 2015.

INCLUDE WHEN CITING DOI: 10.3171/2015.5.FOCUS1514.

DISCLOSURE The authors report no conflict of interest concerning the materials or methods used in this study or the findings specified in this paper. 
Three-dimensional and high-resolution contrast-enhanced CT angiography (CTA)-based navigation with maximum projection multiplanar reformatted imaging might be helpful for preoperative planning and surgical/intraoperative guidance.

\section{Myelography}

Myelography provides visualization of the contour of the spinal cord, which, either with conventional radiography or CT, reveals a spinal mass as a complete or partial block in the flow of the intrathecal contrast material. The historic classification of spinal tumors is based on the use of myelography, with 3 main groups: extramedullary extradural, intradural extramedullary, and intradural intramedullary ${ }^{61}{ }^{1}$ The so-called "meniscus-sign" describing the silhouette of the lesion against the opacified cerebrospinal fluid (CSF) is typical of intradural extramedullary lesions compressing the spinal cord. With larger lesions, a "complete myelographic block" may occur (Fig. 1a and b). However, only the spinal cord contours are delineated with myelography and no information is obtained concerning the composition of the lesion.

\section{Magnetic Resonance Imaging}

Currently, MRI is considered the state-of-the-art imaging modality for spinal cord disease and the diagnostic procedure of choice for the evaluation of spinal tumors. ${ }^{102}$ The multiplanar capability and high soft-tissue resolution of MRI make it the ideal modality for the evaluation of the spinal canal contents, localizing lesions, and assisting in preoperative planning.

Contrast-enhanced MRI defines the relationship of the tumor to the spinal cord, nerve roots, and thecal sac. It aids in differentiating tumor from perilesional edema and cysts, in determining tumor extent, and in evaluating intrinsic spinal cord signal abnormalities.,6,11,57,97 An additional advantage of MRI is the ability to perform high-quality imaging such as 3D sequences for treatment planning and surgical navigation, diffusion tensor tractography (DTI), susceptibility-weighted imaging (SWI), perfusion-weighted imaging (PWI), measurement of the apparent diffusion coefficient (ADC), and MR spectroscopy (MRS). ${ }^{30,60}$

The MR technique must systematically include T1and T2-weighted imaging and gadolinium-enhanced T1weighted imaging with fat suppression. The entire spinal cord must be studied with dedicated phased-array spinal surface coils. At least 2 different imaging planes must be used to locate the tumor properly and to differentiate intra- from extramedullary tumors. ${ }^{57,97}$ Gradient-recalled echo (GRE) sequences and SWI are more sensitive than T1- and T2-weighted imaging in detecting hemorrhage. The short-time inversion recovery (STIR) sequence is excellent for evaluating bone marrow and soft-tissue edema, tumor, and intramedullary lesions. MR myelography (MRM), with or without intrathecal gadolinium administration ( $0.25 \mathrm{ml}$ Gadovist), provides images comparable to those obtained by conventional myelography. Its limitations have been described in the assessment of far-lateral nerve root compression and in cases of isolated epidural fat compression. When performed without an intrathecal contrast agent, MRM utilizes a very heavily weighted T2-weighted sequence to produce a robust paradoxical hyperintense edge between the CSF and the soft tissue of the spinal cord and nerve roots. DTI tractography maps can help differentiate destructive intramedullary tumors from tumors that displace normal tissue. It allows the visualization of the location, orientation, and anisotropy of the white matter tracts. ${ }^{30,100}$ Subsequent surgical planning by the means of high-resolution DTI sequences could decrease surgical morbidity.

Magnetic resonance angiography (MRA) with 3D ca-
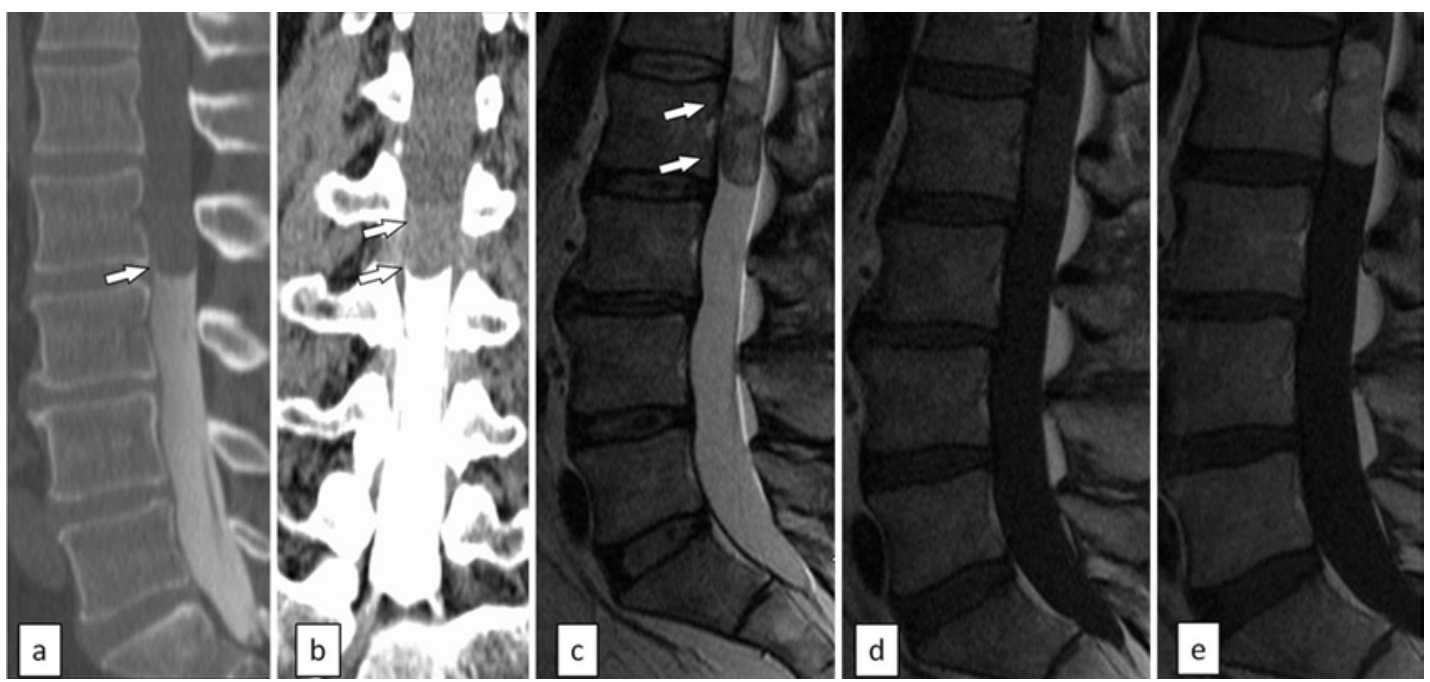

FIG. 1. Schwannoma of cauda equina in a 42-year-old male patient with low-back pain radiating to the legs. Multiplanar reconstructions of CT myelography in sagittal (a) and coronal (b) views reveal a meniscus of contrast (white arrows), indicating the presence of an intradural extramedullary mass lesion in the spinal canal at the L-2 level. A complete myelographic block is noted above the mid-L-2 vertebral level. The corresponding MRI appearance of a "meniscus sign" is demonstrated in the sagittal T2-weighted image (c; white arrows); of note, there are no intradural flow-voids. T1-weighted images obtained before (d) and after gadolinium administration (e) demonstrate a well-defined tumor with moderate homogeneous enhancement. Courtesy of Associate Professor of Radiology, Dr. Santanu Chakraborty, MBBS, MRCP, DMRD, FRCR, University of Ottawa. 
pabilities, including time-of-flight (TOF), phase-contrast (PC), and contrast-enhanced MRA techniques, should be performed in cases of suspected vascular tumors or malformations ${ }^{73}$ and clinical signs of myelopathy. It can help distinguish, localize, and visualize the angiographic architecture of vascular malformations and spinal cord tumors. The noninvasive direct visualization of the arterial feeder(s) provided by MRI/MRA is useful information for endovascular treatment planning by guiding selective catheterization to specific spinal levels.

\section{Digital Subtraction Angiography}

Although rarely used as a primary diagnostic modality for spinal tumors, spinal digital subtraction angiography (DSA) has been the gold standard in the evaluation of intraspinal tumor vascularity which is essential to the successful resection of potentially curable lesions. ${ }^{41}$ Preoperative spinal DSA may be performed when a vascular intraspinal lesion is suspected (based on the clinical presentation and cross-sectional imaging), to characterize the vascular anatomy, and to determine whether the lesion would be amenable to preoperative embolization. DSA can facilitate the embolization of feeding arteries prior to resection in selected cases.

The choice regarding routine DSA for the preoperative assessment of vascular intraspinal tumors varies among institutions. For many authors, MRI is the diagnostic technique of choice, ${ }^{27,55,98}$ while others only perform DSA if preoperative embolization is indicated. ${ }^{12,52,77}$ Other investigators ${ }^{15,85}$ state that diagnostic DSA allows a detailed assessment of the angiographic architecture of the lesion and adjacent vascular structures and is helpful in establishing the differential diagnosis and the treatment planning.

Identification of feeding vessels can guide resection and avoid inadvertent spinal cord ischemia. ${ }^{41}$ In our experience, for instance, vascular intraspinal tumors affecting the cauda equina require detailed preoperative DSA to distinguish whether the lesion arises from the spinal nerves or from the filum terminale. This distinction is seldom possible to obtain using noninvasive vascular techniques. The neuroradiologist can distinguish a lesion that arises from the filum terminale by assessing its vascular supply via the anterior spinal artery. In these cases, preoperative embolization is very risky because it can compromise the supply to the spinal cord. The vascular mapping provided by DSA will help the surgeon to avoid an injury to the supply to the spinal cord during the resection of the tumor. ${ }^{92}$

\section{Clinical and Imaging Diagnosis of Vascular Intraspinal Tumors Hemangioblastoma \\ Prevalence}

Spinal hemangioblastomas are uncommon, accounting for approximately $1 \%-5 \%$ of all spinal cord tumors. There is no sex predilection. The peak incidence is in the fourth decade. ${ }^{52}$ As with intracranial hemangioblastomas, one third of the patients have von Hippel-Lindau (VHL) disease. Most of the lesions are solitary, but multiplicity is seen in up to $20 \%$ of cases. Patients with VHL disease tend to develop new lesions and present with neurologi- cal symptoms at a younger age than patients with sporadic disease. ${ }^{12}$ The thoracic spinal cord is most frequently involved (51\%), followed by the cervical spinal cord (41\%). Only $8 \%$ of spinal hemangioblastomas are in the caudal region of the spinal cord. Hemangioblastomas may originate from any compartment of the spinal canal or within a vertebral body: $60 \%$ are intramedullary, $11 \%$ are intraand extramedullary, $21 \%$ are intradural extramedullary, and $8 \%$ are extradural. ${ }^{16}$

\section{Clinical Presentation}

Symptoms of sensory changes, motor dysfunction, and pain commonly accompany hemangioblastomas. The earliest symptom of sensory change is usually due to the impairment of proprioception related to the tumor's location in the dorsal area of the spinal cord. ${ }^{68,107}$ The mean duration between symptom onset and presentation is approximately 30 months, reflecting the slow and indolent pattern of tumor growth. ${ }^{52}$ For patients with VHL syndrome, retinal or cerebellar findings usually precede the spinal cord manifestation. Rarely, spinal hemangioblastomas may be a source of subarachnoid hemorrhage or hematomyelia.

\section{Pathological Characteristics}

Hemangioblastomas are located mainly on the dorsal surface of the cord. At gross examination, spinal cord hemangioblastomas most commonly appear as highly vascular, discrete, nodular, reddish masses abutting the leptomeninges, with prominent dilated and tortuous vessels on the surface of the spinal cord (Fig. 2a). Histologically, a hemangioblastoma is composed of a highly vascular solid portion with small arteries, capillaries, and large dilated draining veins. Its nidus consists mainly of endothelial cells and interspersed large, pale stromal cells ${ }^{50}$ (Fig. 2b).

Genetically, VHL disease is caused by germline mutations of the VHL tumor-suppressor gene located on the distal part of the short arm of chromosome 3 (3p25-26). This gene, encoding for a 213-amino acid protein, plays a major role in the regulation of vascular endothelial growth factor expression, which explains the highly vascular nature of the hemangioblastomas. ${ }^{12,25}$

\section{Imaging Features}

MRI ensures an accurate diagnosis of spinal hemangioblastomas and associated cysts. In addition, it offers excellent visualization of multiple lesions and is the best imaging modality for follow-up. Dilated tortuous feeding arteries and draining pial veins are seen on half of the myelographic studies of hemangioblastomas. An unenhanced CT scan may reveal a hypodense partially cystic mass.

The typical appearance of a hemangioblastoma is that of a large intramedullary cyst with a mural nodule. $3,5,12,13,19,20$, $50,57,97$ The signal intensity is variable on T1-weighted images, with the majority of these lesions being iso- to hypointense and difficult to differentiate from the normal spinal cord. ${ }^{5,102}$ Small tumors (less than $10 \mathrm{~mm}$ in maximum dimension) are often isointense on T1-weighted images and demonstrate homogeneous contrast enhancement. Larger lesions tend to be hypointense or mixed, iso- and hypointense, on T1-weighted images, with heterogeneous enhancement. . $5,20,57$ These larger lesions are iso- to hyper- 


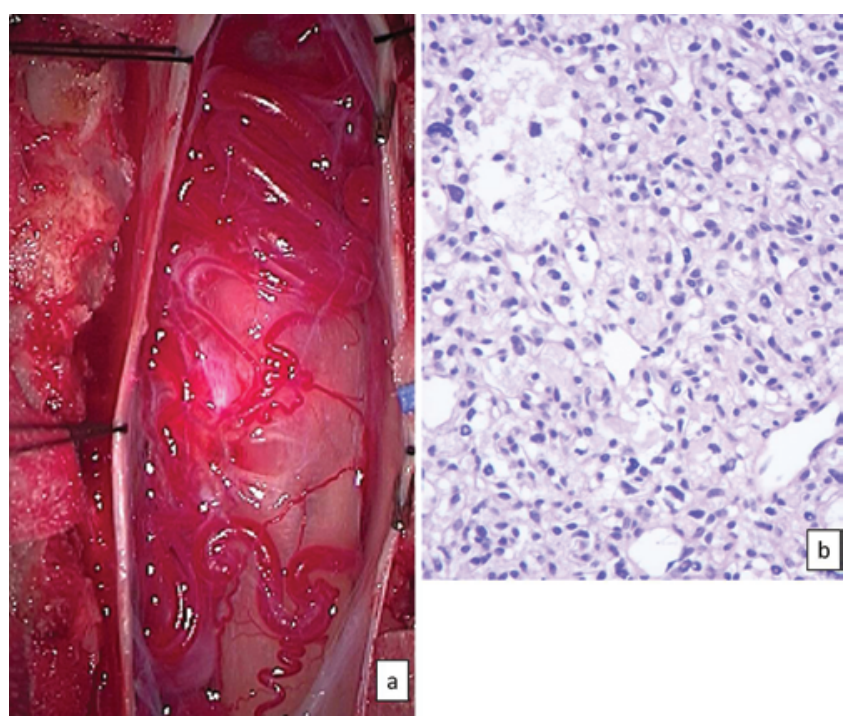

FIG. 2. Intradural extramedullary hemangioblastoma. The photograph of the surgical exposure (a) shows serpentine vascular congestion with arterialized radicular and perimedullary veins. The photomicrograph (b) shows sheets of tumor cells with clear cytoplasm and scattered blood vessels. $H$ \& E, original magnification $\times 200$.

intense on T2-weighted images. Associated cysts can be of varying signal intensity depending on the protein content. ${ }^{57,97}$ When the lesions are solid, extensive surrounding edema is usually demonstrated. ${ }^{6}$ The edema may extend far beyond the solid tumor and may in part be due to venous congestion or arteriovenous shunting..$^{13}$ An extensive syrinx (a cystic cavity within the spinal cord) - and/ or syringohydromyelia (intramedullary fluid that dissects into the surrounding white matter forming a cystic cavity or syrinx)-is another typical associated finding. The syringohydromyelia is always found to have a relatively large size as compared with the size of the intramedullary tumor. Symptomatic small hemangioblastomas can have relatively large associated syringes, whereas asymptomatic ones usually do not. ${ }^{20}$

Serpentine flow voids corresponding to large feeding or draining vessels can be seen along the dorsal aspect of the cord on both T1- and T2-weighted images. These flow voids can simulate a vascular malformation. . $57,105^{-50}$ Chu et al. ${ }^{20}$ reported the presence of vascular flow voids in or around medium-sized to large tumors. The vascular flow voids were absent when the tumor was less than 15 $\mathrm{mm}$ in maximum dimension, whereas they were invariably present when the tumor size was $25 \mathrm{~mm}$ or greater. A "cap sign" may be seen on T2-weighted images (Fig. 3a), preferably obtained with gradient-echo sequences. The dark cap representing hemosiderin deposition appears as a hypointense rim on T2-weighted images at the rostral and caudal tumor regions. 3D MRA can provide important preoperative information as a noninvasive procedure by demonstrating greater detail in the architecture of the feeding/draining vessels. There is no difference in the MRI appearance of hemangioblastomas between patients with (Figs. 3-6) or without (Fig. 7) VHL disease except for the multiplicity and higher percentage of small tumors in patients with VHL disease ${ }^{20}$ (Fig. 4).
Spinal DSA plays an important role in surgical planning prior to a hemangioblastoma resection, especially when the lesion is large or extremely hypervascular. Spinal DSA often demonstrates enlarged feeding arteries, early draining veins, and intense nodular stains. The findings help differentiate the hemangioblastoma from other pathological entities, such as an ependymoma or a vascular malformation. ${ }^{1}$ As such, a highly vascular mass with dense prolonged blush and prominent draining veins are the typical features of hemangioblastoma noted in DSA (Fig. 6).

\section{Differential Diagnosis}

The clinical features and unenhanced MRI appearance of intramedullary hemangioblastoma and ependymoma are similar. Large, exophytic intramedullary hemangioblastomas, and the less common extramedullary hemangioblastomas, may mimic nerve sheath tumors on images. Ependymoma and nerve sheath tumors (Fig. 1) can be ruled out by the vascular markings in MRI and tumor vessels on angiography. ${ }^{95,105}$ As for vascular lesions of the spinal canal, arteriovenous malformations and renal cell carcinoma should be carefully differentiated. Intradural perimedullary fistulas are usually located in the thoracolumbar region and are characterized by a single shunt without a nidus between the spinal artery and the spinal vein. ${ }^{95,108}$ Dural arteriovenous fistulas usually have a small nidus situated in the dural sac in the intervertebral foramen that is fed by radicular arteries..$^{15,95,108}$ Spinal cord vascular malformations are rarely accompanied by syringohydromyelia and solid enhancement on MRI. ${ }^{52,105}$ As for renal cell carcinoma, it can probably be ruled out on the basis of preoperative imaging.

\section{Paraganglioma}

\section{Prevalence}

Paragangliomas, also called chemodectomas and glomus tumors, represent extraadrenal neuroendocrine tumors originating from the autonomic nervous system. ${ }^{61}$ Paraganglioma in the spinal canal, believed to be rare, is predominantly of the sympathetic type. The first description of a paraganglioma of the filum terminale was published in 1970 by Miller and Torack, ${ }^{63}$ and the lesion was initially misdiagnosed as a secretory ependymoma. In 1972, Lerman et al. reported a ganglioneuroma-paraganglioma, using present terminology, of the filum terminale..$^{54}$

According to the literature, ${ }^{33,50,62,88,93}$ spinal paragangliomas are found more frequently in the intradural extramedullary compartment and have a high affinity for the cauda equina or filum terminale. Less common sites include cervical and thoracic regions. Vertebral, extradural, and intramedullary sites of origin are much less common. ${ }^{56,64}$ Paragangliomas are more commonly encountered in patients of 50-60 years of age. These tumors are extremely rare in childhood.

\section{Clinical Presentation}

The clinical presentation of patients with spinal paraganglioma is largely nonspecific, and signs and symptoms are always due to spinal cord or nerve root compression. 

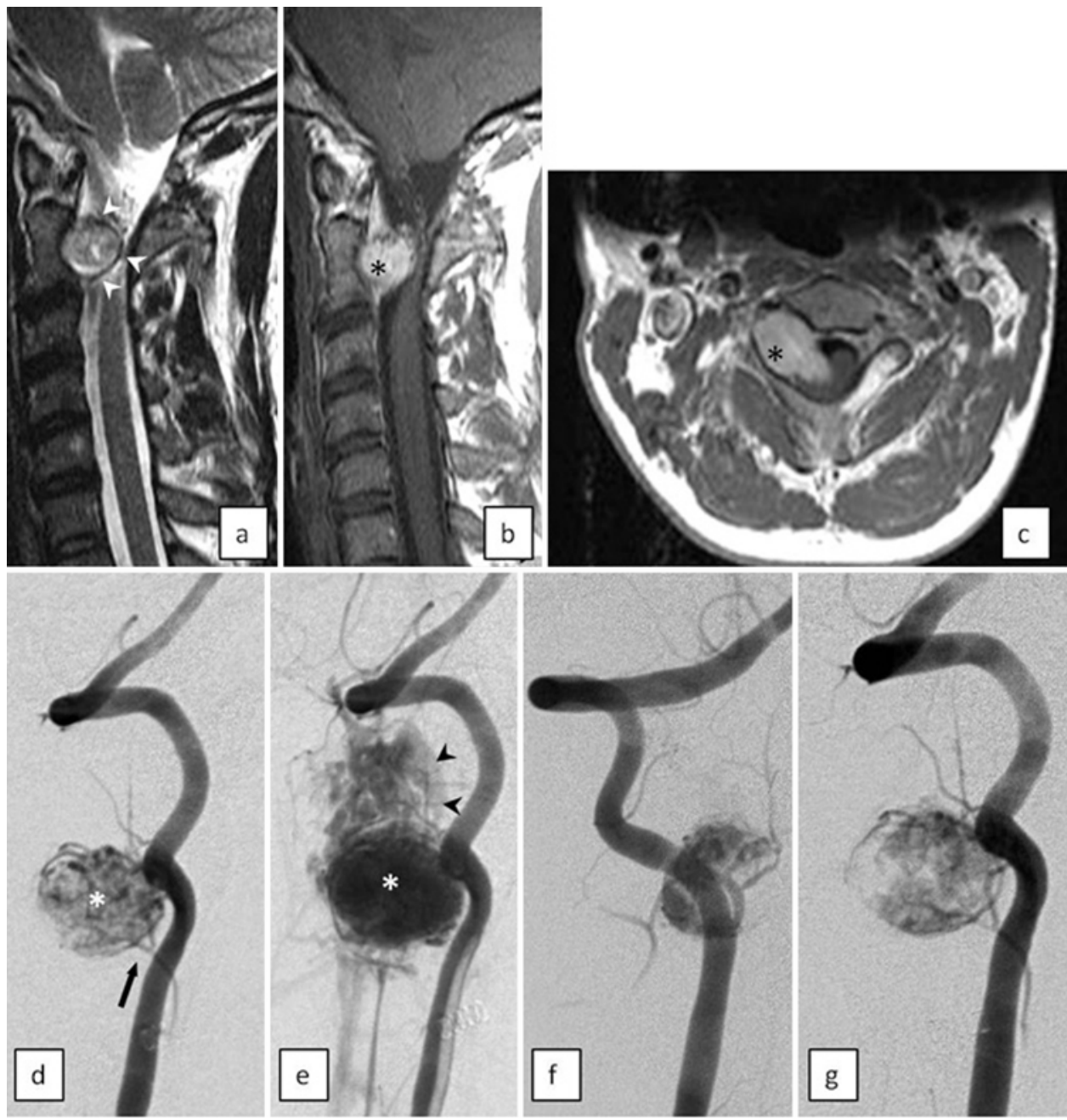

FIG. 3. Cervical extradural hemangioblastoma in a 36 -year-old male patient with VHL disease. The sagittal T2-weighted MR image (a) demonstrates an extradural mass with a hypointense rim (cap sign, white arrowheads). Serpentine flow voids along the spinal cord surface are also revealed. Sagittal (b) and axial (c) contrast-enhanced T1-weighted MR images show homogeneous enhancement of the mass (black asterisks). Pre-embolization angiography of the right vertebral artery (d, arterial phase; e, venous phase) demonstrates prolonged tumor blush with radicular artery supply (d, black arrow) and drainage to perimedullary veins (e, black arrowheads). The white asterisks indicate tumor blush. Postembolization angiography (f and g) shows prominent devascularization after intratumoral NBCA deposition.

As for tumors of the cauda equina or filum terminale, the most common symptoms on presentation are lower back pain and sciatica ${ }^{4,62,88,93}$ with a mean duration of 4 years. Sensory or motor deficits have been noticed in $35 \%$ of cases. Sphincter dysfunction is rare. Paraplegia, numbness, and back tenderness have been reported.

Paragangliomas, unlike adrenal pheochromocytomas, are nonchromaffin and rarely produce catecholamine. Thus, systematic manifestations (weight loss, hypertension, flushing, sweating, tremors, tachycardia, nausea, vomiting, etc.) are seldom seen in patients with primary spinal paraganglioma.

\section{Pathological Characteristics}

On gross examination, ${ }^{50}$ paragangliomas are soft, encapsulated, rose-red to brown colored masses that may be slightly hemorrhagic (Fig. 8a). Prominent vascularity in the form of numerous feeding arteries is common. They are typically oval to sausage shaped and are attached to either the filum terminale or less often to a caudal nerve root. Microscopically, $49,66,75$ paragangliomas have a biphasic histological pattern composed of chief cells and sustentacular (supporting) cells. The most common feature is a uniform population of small, round, polyhedral, cuboidal to cylindrical, or columnar cells, which form compact nests known as "zellballen," surrounded by dense connective tissue containing a delicate and extensive network of endothelium-lined vessels (Fig. 8b). A fibrous capsule is a common finding, correlating with a decreased rate of recurrence. Recurrence is much more common in unencapsulated paragangliomas.

The characteristic immunohistochemical profile is a positive staining for various endocrine markers, including NSE (neuron-specific enolase), synaptophysin, chromogranin, S-100, and GFAP (glial fibrillary acidic protein). ${ }^{49,66}$ 


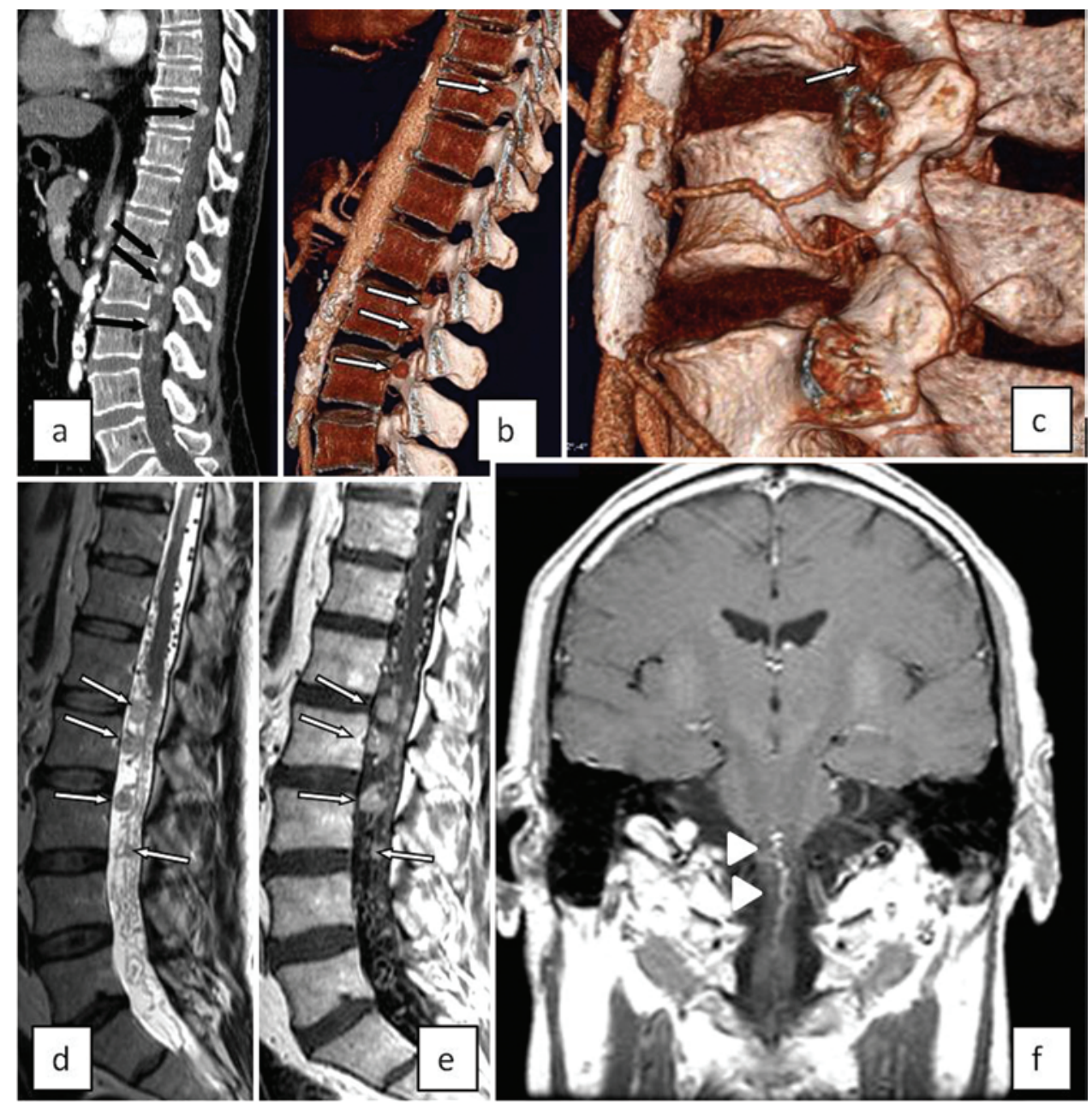

FIG. 4. Multiple hemangioblastomas in a patient with VHL disease. The sagittal CTA image (a) and volume rendering reconstruction images ( $\mathbf{b}$ and $\mathbf{c}$ ) demonstrate enhancing nodules (black \& white arrows) representing multiple hemangioblastomas. The sagittal T2-weighted image (d) and contrast-enhanced sagittal and coronal T1-weighted images (e and f, respectively) show multiple mural nodules (white arrows) of the hemangioblastomas associated with prominent perimedullary veins (white arrowheads).

\section{Imaging Features}

Radiographically, paragangliomas are fairly nonspecific. Findings on plain radiographs and CT scans include bone erosion (scalloping), widened interpedicular distance, flattening of the pedicles, and concave deformity of the dorsal margin of lumbar vertebral bodies, which are signs of a slowly growing lesion..$^{62}$ Scoliosis and spondylolisthesis have been reported sporadically. On CT images, paragangliomas appear as isodense masses with homogeneous enhancement due to their rich vascularization. ${ }^{53,75}$ Although the myelographic findings are nonspecific, complete block or serpiginous defects are commonly observed.

On MRI, paragangliomas are isointense on T1-weighted sequences and hyperintense on T2-weighted sequences relative to the spinal cord. After gadolinium administration, there is an intense homogeneous enhancement. ${ }^{50,62,88,93}$ A hypointense rim (cap sign) is usually seen on T2-weighted images ${ }^{51}$ which is suggestive of an intradural well-encapsulated tumor and is attributed to the paramagnetic effect of hemosiderin or ferritin from previous hemorrhages (Fig. 9). A characteristic "salt-and-pepper" appearance on T2-weighted images is common in neck and skull base paragangliomas. This appearance is attributed to the hypervascularity of these lesions, which results in punctuate areas of flow void interspersed in a matrix of increased signal intensity caused by slow flow and tumor cells. Serpiginous flow void along the surface and within the tumor nodule is a frequent feature attributed to the hypervascularity of the lesion or to the congested veins, which are compressed by the mass ${ }^{88}$ (Fig. 10). Nonetheless, small tumors tend not to show the flow void phenomenon. Associated syringohydromyelia has been reported. ${ }^{33}$

Angiographic images reveal an intense early blush that persists well into the arterial and venous phases ${ }^{53}$ helping to differentiate paragangliomas from arteriovenous shunts.

\section{Differential Diagnosis}

The specific preoperative diagnosis of paragangliomas is almost impossible, unless the presence of systematic manifestations leads to the detection of high urinary levels of biogenic amines or their metabolities. ${ }^{18,106}$ If history can exclude a metastasis, the differential diagnosis is mainly focused on ependymoma, schwannoma (Fig. 1), and hemangioblastoma. However, differentiation of paraganglio- 


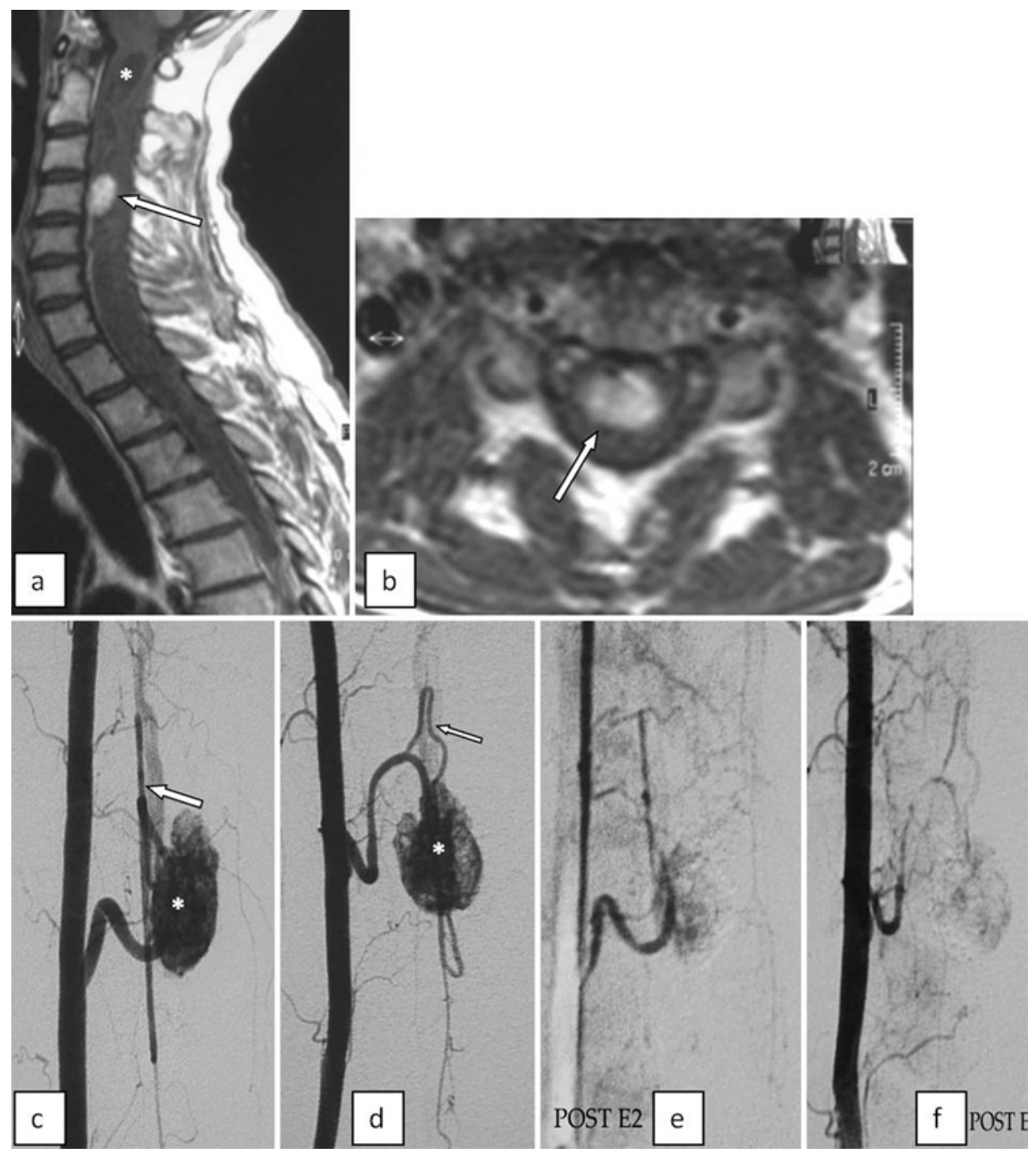

FIG. 5. Hemangioblastoma in a 34-year-old male patient with VHL disease and progressive sensitivity and motor deficit of the right upper limb. Contrast-enhanced MR images show the rare ventral location of the hemangioblastoma ( $\mathbf{a}$ and $\mathbf{b}$, white arrows) associated with syringomyelia (a, white asterisk). Angiography of right vertebral artery shows that the tumor (c and d, white asterisks) is mainly fed by the anterior spinal artery (c and d, white arrows). Posttreatment angiograms obtained after intratumoral NBCA/ethiodized oil embolization (e and f) reveal a significant devascularization of the tumor. Panels $\mathrm{c}$, $\mathrm{f}$, and e are reproduced from Springer Neuroradiology 50:145-151, Embolization of intradural vascular spinal cord tumors, Rodesch et al., Fig. 1, with kind permission from Springer Science and Business Media.

mas from these tumors by imaging techniques is frequently quite difficult because of considerable overlap in their imaging findings.

\section{Meningioma}

Prevalence

Spinal meningioma accounts for approximately $25 \%-$ $46 \%$ of primary spinal tumors, secondary only to nerve sheath tumors in frequency. ${ }^{35,58,79,91}$ There is a female predominance of 3-4:1. These tumors are extremely rare in children. The age of patients at presentation ranges mostly between 40 and 70 years with a peak between the 5th and 6th decades. ${ }^{35,58,79,91}$ Most spinal meningiomas (90\%) are intradural extramedullary; only $10 \%$ are extradural or dumbbell tumors. Occurrence of spinal meningioma in the intramedullary compartment is extremely rare. Approxi- mately $80 \%$ of spinal meningiomas are found in the thoracic region, with less common involvement of the cervical $(15 \%)$ and lumbar $(5 \%)$ segments. In men, however, 50\% are in the thoracic region and another $40 \%$ are cervical. Most spinal meningiomas are located posterolaterally in the thoracic region and anteriorly in the cervical region. ${ }^{1,13,97}$

\section{Clinical Presentation}

Spinal meningiomas are slow-growing tumors that produce signs and symptoms through progressive compression of the spinal cord and adjacent nerve root. Pain is the most common symptom, ${ }^{35,79,91}$ with radicular, funicular, or localized back pain being predominant. Significant weakness (paresis or paralysis) and sensory loss (hypoesthesia, paresthesia or anesthesia) are the next most common symptoms. 


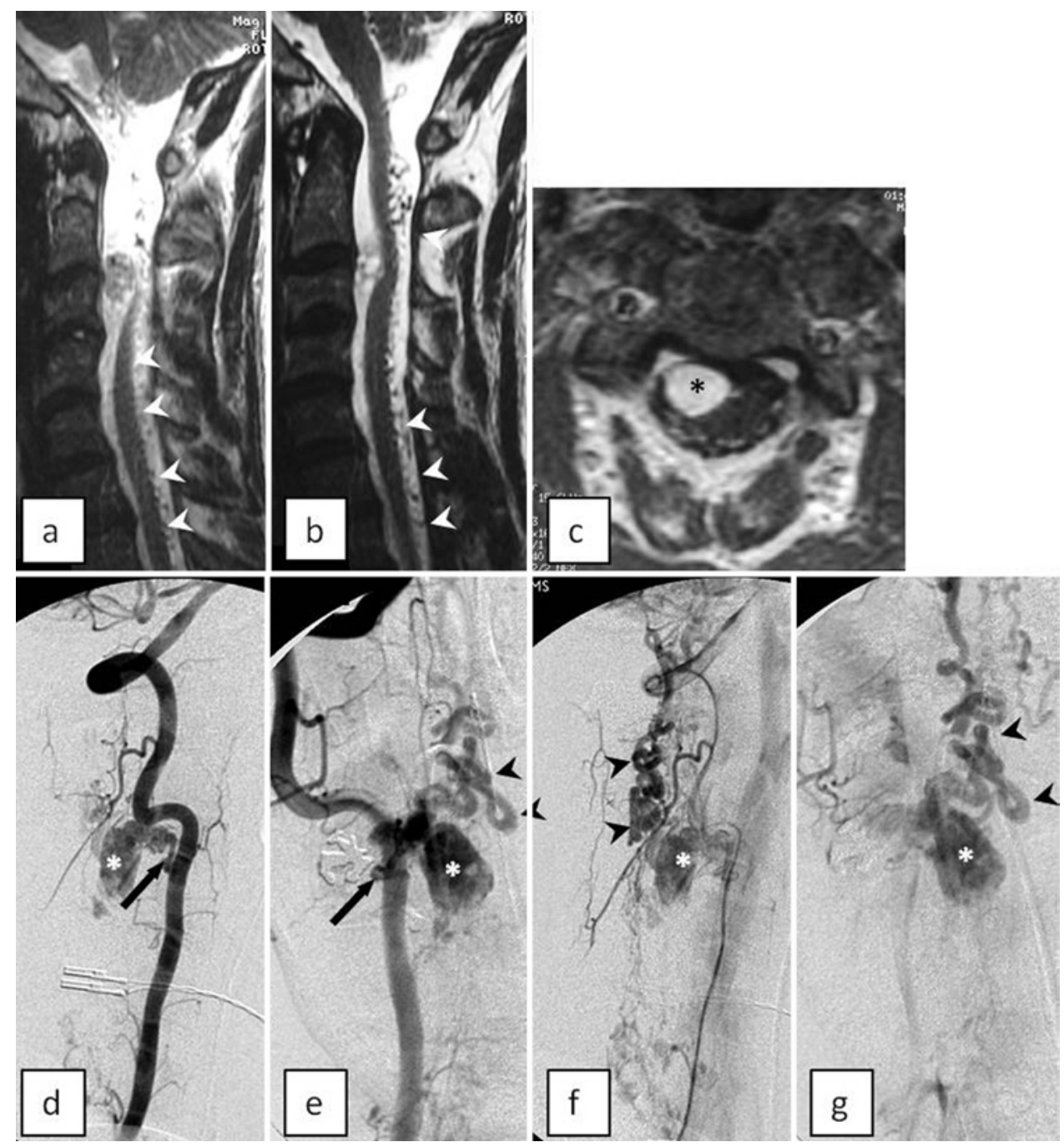

FIG. 6. Cervical intradural extramedullary hemangioblastoma. Sagittal T2-weighted images (a and b) demonstrate serpentine flow voids (white arrowheads) along the spinal cord surface. An intensely enhancing tumor is noted in the axial T1-weighted image obtained after contrast administration (c, black asterisk). Arterial phase images of right vertebral angiography show dense tumor blush ( $\mathbf{d}$ and $\mathbf{e}$, white asterisks) that persists into the venous phase (f and $\mathbf{g}$, white asterisks) with posterior spinal artery supply ( $\mathrm{d}$ and e, black arrows) and drainage to prominent perimedullary veins (e-g, black arrowheads).

\section{Pathological Characteristics}

Menigiomas are usually solitary lesions. Multiple meningiomas are always associated with multiple inherited schwannomas meningiomas and ependymomas (MISME) syndrome ${ }^{89}$ Similar to their intracranial counterparts, spinal meningiomas comprise 15 histological subtypes, with the majority being meningothelial or psammomatous in type. Most spinal meningiomas are benign tumors (WHO Grade I); however, rare histological variants, namely clear cell and choroid meningioma (WHO Grade II) and anaplastic (WHO Grade III), have a significantly higher risk of local recurrence and aggressive biological behavior. ${ }^{83}$ Benign meningiomas are round, bosselated, or lobulated well-demarcated dural-based nodules (Fig. 11a). Depending on their collagen content, the consistency of these tumors ranges from rubbery to firm. Histologically, psammomatous meningioma is the most prevalent benign spinal biotype, followed by meningothelial and transitional ${ }^{96}$ (Fig. 11b). When compared with intracranial meningiomas, spi- nal meningiomas embody distinct patterns of gene expression and genetic abnormalities, such as a higher predominance of single tumor cell clones (monosomy 22). ${ }^{84}$

\section{Imaging Features}

Unlike intracranial meningiomas, spinal meningiomas may not be associated with secondary osseous changes. Foraminal widening and pedicular erosion may occasionally be present. The tumor may be calcified, and heavy calcification may be seen.

Most spinal meningiomas are well delineated. On T1weighted imaging, most tumors tend to be iso- to hypointense relative to the spinal cord. These lesions are slightly hyperintense on T2-weighted images (Fig. 12). Calcification results in low T1- and low T2-weighted signal intensity. Intense enhancement is immediate and homogeneous after contrast administration, except for calcified areas. ${ }^{1,13}$, ${ }^{84,97}$ In addition, there may be an associated thin region of enhancement that is contiguous with the dura mater; this 

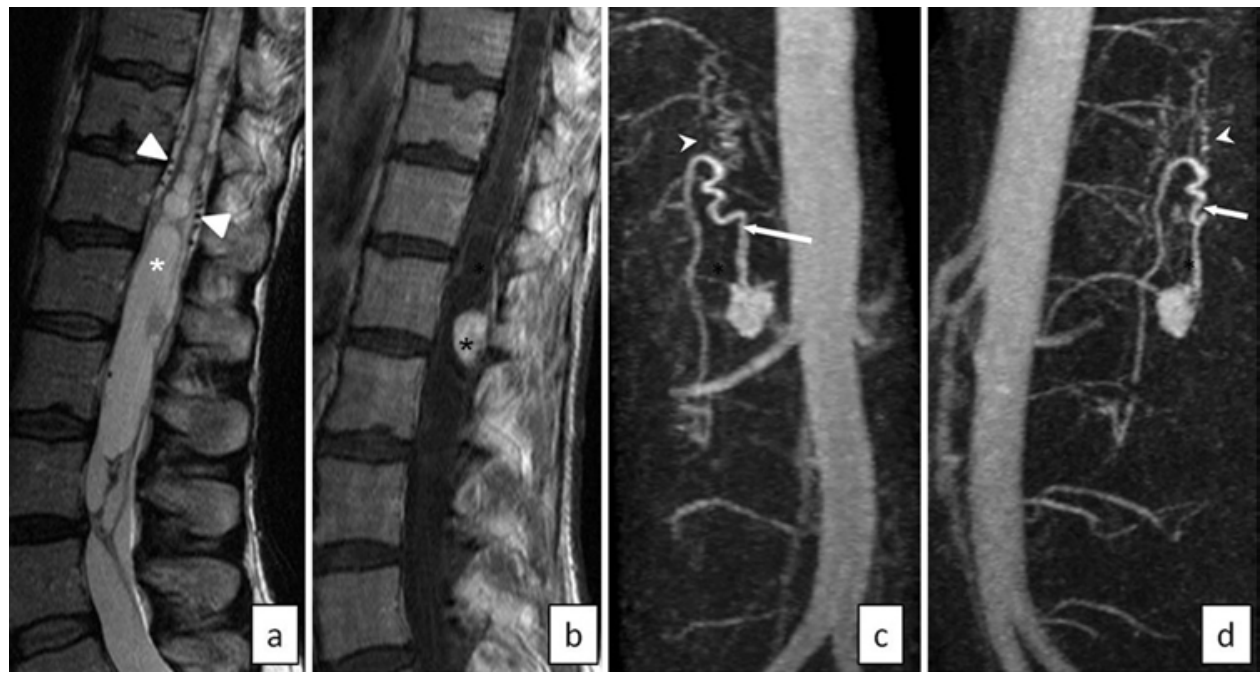

FIG. 7. Intramedullary hemangioblastoma of the conus medullaris in a 48-year-old female patient with a 2-year history of progressive pain in the scapular region and left leg. The sagittal T2-weighted MR image (a) demonstrates extensive syringohydromyelia (white asterisk) with marked expansion of the spinal cord. The conus medullaris is low lying at the L-3 level. Prominent flow voids (white arrowheads) are evident along the surface of the distal thoracic cord proximal to the lesion. The contrast-enhanced sagittal T1-weighted image (b) reveals a strongly enhancing mass (black asterisk). Contrast-enhanced MRA maximum intensity projection (MIP) images (c and d) demonstrate the mural nodule (black asterisk) receives blood supply from a prominent lumbar radicular artery (white arrows). Note that a few prominent perimedullary veins are evident (white arrowheads).

has been called a "dural tail" sign (Fig. 12c). A syrinx can occur in rare cases of intramedullary meningiomas. ${ }^{81}$

The angiographic characteristics of spinal meningiomas are similar to those of intracranial meningiomas, with an important feature being the long duration of the tumor stain persisting into the venous phase. ${ }^{88}$ Pseudo-continuous arterial spin labeling (PCASL) represents a novel imaging technique reported useful in reliably assessing meningioma vascularity and tumor blood flow. ${ }^{51}$

\section{Differential Diagnosis}

The differential diagnosis on the basis of imaging char-
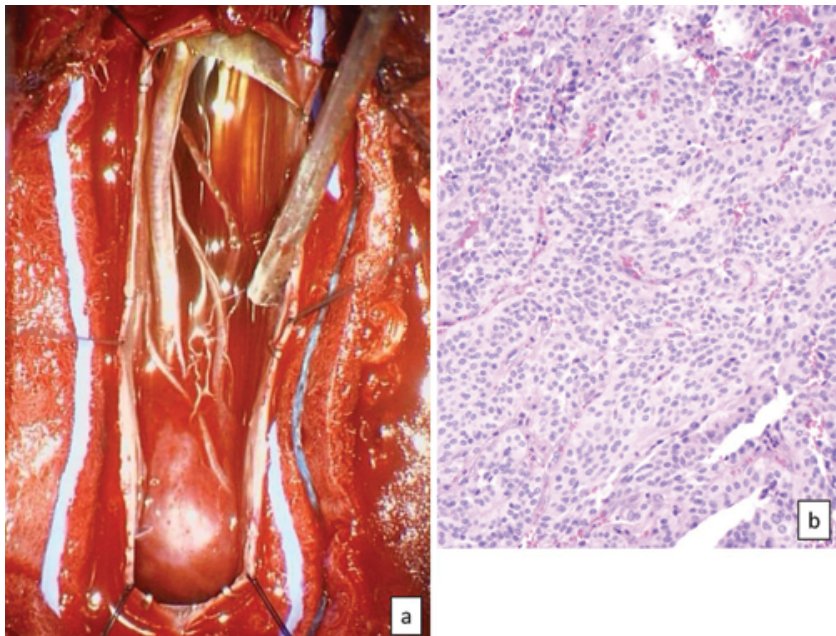

FIG. 8. Paraganglioma. The intraoperative image obtained during resection of an intradural paraganglioma (a) shows an oval, encapsulated, rose-red to brown hemorrhagic mass with prominent vascularity. The photomicrograph (b) of a section of the tumor shows nests of cells surrounded by connective tissue containing many blood vessels in a zellbalen pattern. $\mathrm{H}$ \& E, original magnification $\times 200$. acteristics includes schwannoma, neurofibroma, and metastasis. De Verdelhan et al. ${ }^{28}$ suggested that a diagnosis of schwannoma should be favored over meningioma when a cervical or thoracic intradural extramedullary tumor shows hyperintensity on T2-weighted images or intense enhancement without a dural tail sign. Lack of foraminal extension favors a diagnosis of meningioma over a diagnosis of schwannoma or neurofibroma. The latter 2 lesions usually demonstrate higher signal intensity on T2weighted images, cystic changes, and inhomogeneous enhancement (Fig. 1). As for intramedullary meningiomas, astrocytomas and ependymomas are also included in the differential diagnosis, because they also tend to exhibit T1weighted signal hypointensity, T2-weighted signal hyperintensity, and variable enhancement with gadolinium.

\section{Neurosurgical Management of Vascular Intraspinal Tumors}

In keeping with the general principles of surgical oncology, maximal safe tumor resection should be the primary objective for the treatment of vascular intraspinal tumors. Thus, adequate preoperative planning and intraoperative neurophysiological monitoring is paramount for maximizing tumor resection and minimizing neurological morbidity. A 50\% decline in the amplitude of the motor evoked potentials represents an indication of a new, permanent postoperative deficit. In contrast, although sensory potentials may decrease in amplitude or disappear after a midline myelotomy, they do not predict postoperative motor function. ${ }^{67,80}$

After a standard midline incision with subperiosteal bony dissection, a laminectomy should be performed at least 1 segment below and above the tumor for optimal visualization. For intramedullary tumors, after the dura mater is exposed, intraoperative ultrasonography can be used 


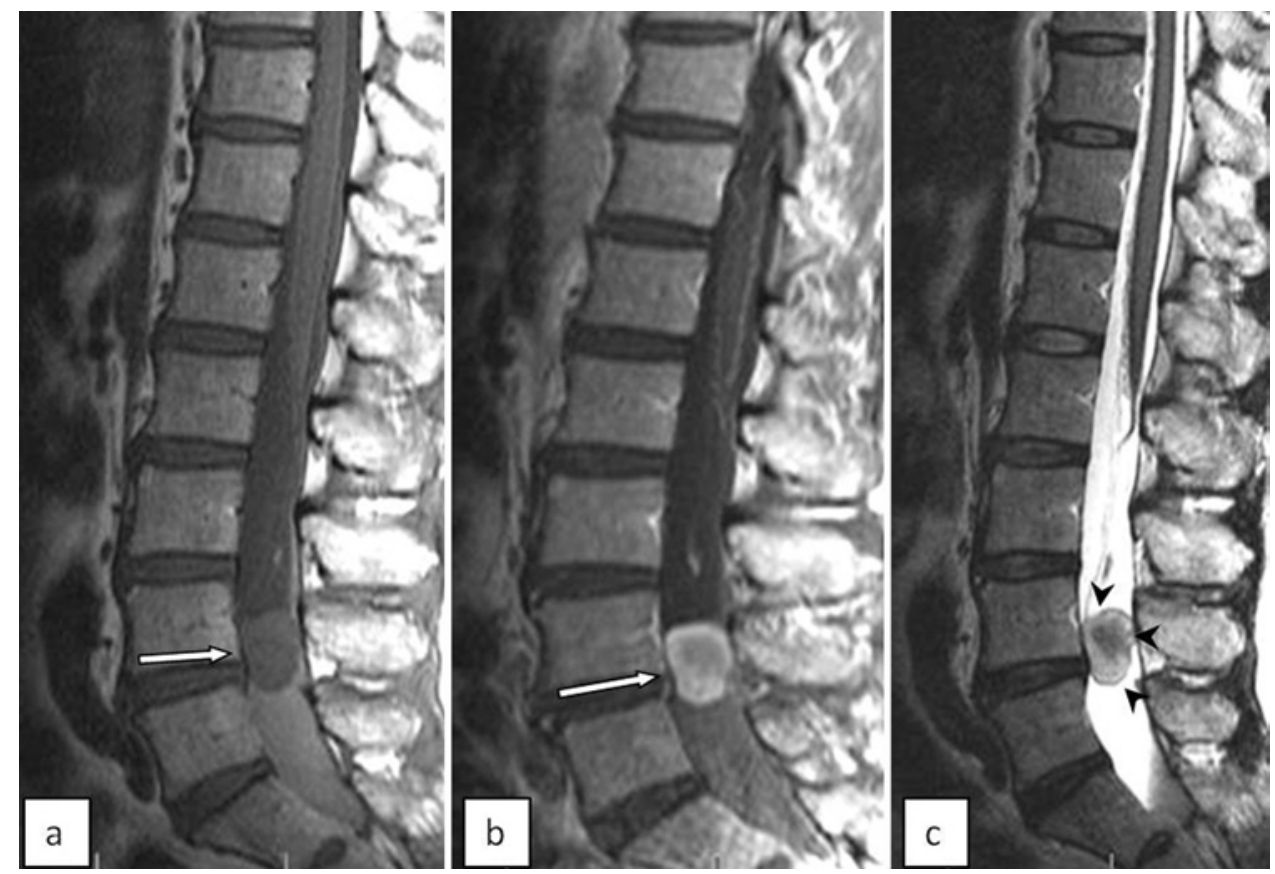

FIG. 9. Paraganglioma in a 38-year-old female patient with a 6-week history of progressive cauda equina syndrome. Sagittal T1weighted image shows an intradural mass lesion (a, white arrow) with heterogeneous enhancement (b, white arrow) after contrast agent administration. T2-weighted image shows hypointense rim (cap sign) of the mass (c, black arrowheads). Reproduced from Springer Surgical Neuroangiography. Vol. 2. Clinical and Endovascular Treatment Aspects in Adults, 2nd ed, New York: SpringerVerlag, 2004, pp 873-911, Ch. 13, Tumors of the spinal column and spinal cord, Berenstein et al., Fig. 13.25, with kind permission from Springer Science and Business Media.

to ensure adequate rostrocaudal exposure of the tumor. A midline myelotomy centered over the dorsal median sulcus, or an approach through the dorsal root entry zone, is then performed according to the location of the lesion..$^{59}$ The degree of complete surgical removal is highly influ- enced by the plane between the tumor and the spinal cord. This interface can be accurately assessed following adequate myelotomy. When the tumor-spinal cord interface is not well visualized despite a myelotomy extending over the entire rostrocaudal extent of the tumor, preservation of
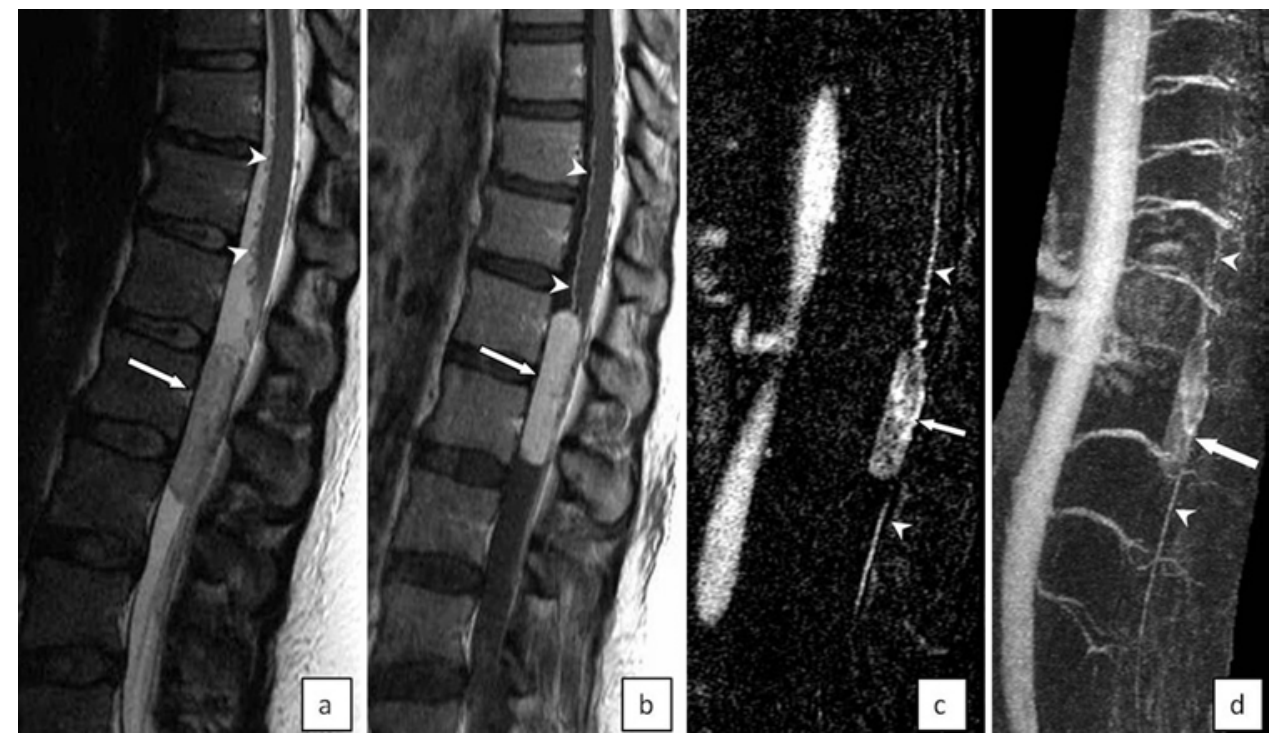

FIG. 10. Paraganglioma of the cauda equina in a 36-year-old female patient with back and lower-extremity pain. The sagittal T2weighted image (a) shows a large hyperintense lesion (white arrow) occupying the spinal canal. The sagittal T1-weighted image obtained after administration of contrast medium (b) reveals intense homogeneous enhancement (white arrow). Multiple curvilinear flow-voids/vessels ( $a$ and $b$, white arrowheads) are seen at the surface of the lower spinal cord and the conus. Contrast-enhanced MRA (c) and MIP images (d) demonstrate the tumor with a lumbar radicular artery supply (white arrows) and prominent perimedullary veins (white arrowheads). 


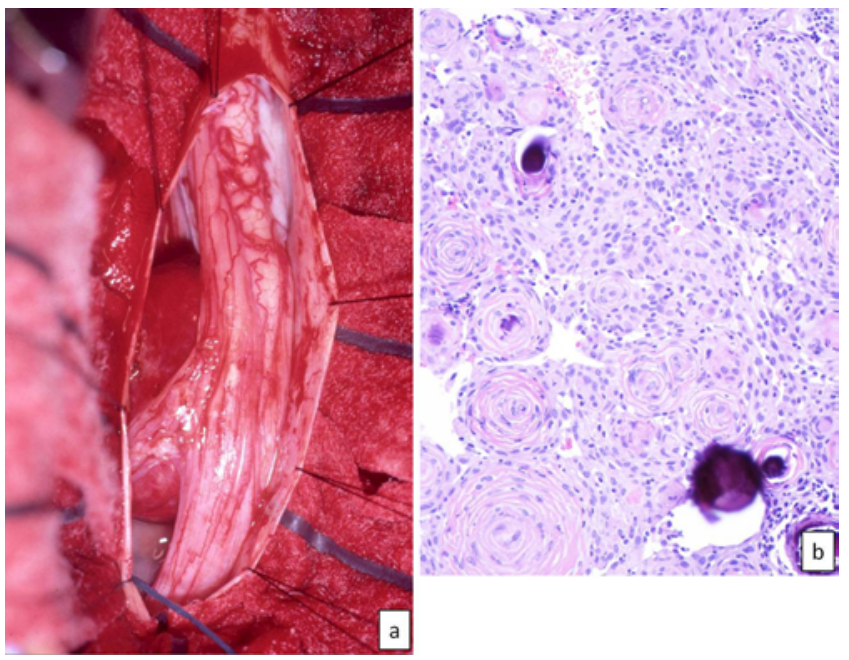

FIG. 11. Intradural meningioma. The intraoperative photograph (a) shows a round, well-demarcated dura-based lesion. The photomicrograph (b) shows meningothelial cells in whirling pattern, psammoma bodies, and vessels. $H$ \& $E$, original magnification $\times 200$.

the spinal cord tissue, rather than gross-total resection, is recommended. ${ }^{8,59} \mathrm{~A}$ clear demarcation between tumor and normal spinal cord tissue depends on the type of tumor. Benign tumors, such as ependymomas and hemangioblastomas, are noninfiltrative lesions with a distinct plane because they are encapsulated. Similarly, unlike intracranial meningiomas, spinal meningiomas do not penetrate the pia mater. The presence of an "intermediate leptomeningeal layer" between the pia and the arachnoid simplifies the resection. ${ }^{82}$ Most spinal hemangioblastomas arise from the dorsal part of the spinal cord, and excising the pial attachment facilitates their resection.
Intraoperative hemorrhage from vascular intraspinal tumors can obscure the operative fields and consequently limit gross-total resection. ${ }^{52}$ Although endovascular embolization can reduce intraoperative blood loss, it is for the most part not routinely performed, as complications were previously reported, including spinal cord swelling, massive venous bleeding, intratumoral hemorrhage, and spinal cord ischemia. ${ }^{24,29,34,40}$ Temporary arterial occlusion (TAO) by aneurysm clip placement with concurrent neuromonitoring is a microsurgical technique that helps to differentiate the arteries supplying the tumor from those supplying the healthy spinal cord. ${ }^{23}$ To our knowledge, no randomized studies exist comparing the resection of nonmetastatic vascular intraspinal tumors with or without preoperative embolization. Nonetheless, several studies reported preoperative endovascular embolization as a safe technique. It decreased intraoperative hemorrhage and caused tumor shrinkage. In addition, the avascular tumor increased the cleavage plane and permitted easier manipulation and resection. $9,32,86$

En bloc resection is another technique reported to significantly reduce the blood loss that occurs despite preoperative embolization. Wu et al. reported that the blood loss during en bloc resection of intraspinal angiomatous meningiomas was significantly less (mean $150 \pm 55 \mathrm{ml}$, range $100-400 \mathrm{ml}$ ) than in piecemeal resection (mean $475 \pm 83$ $\mathrm{ml}$, range 400-600 ml). ${ }^{104} \mathrm{In}$ another review, following the preoperative embolization of 18 hypervascular intraspinal tumors, the estimated blood loss during the surgical procedure ranged between 200 and $6000 \mathrm{ml}$, with an average of $1100 \mathrm{ml}^{86}$

Although there is no consensus in terms of the need for preoperative embolization of vascular intraspinal tumors, this technique seems to safely decrease the intraoperative
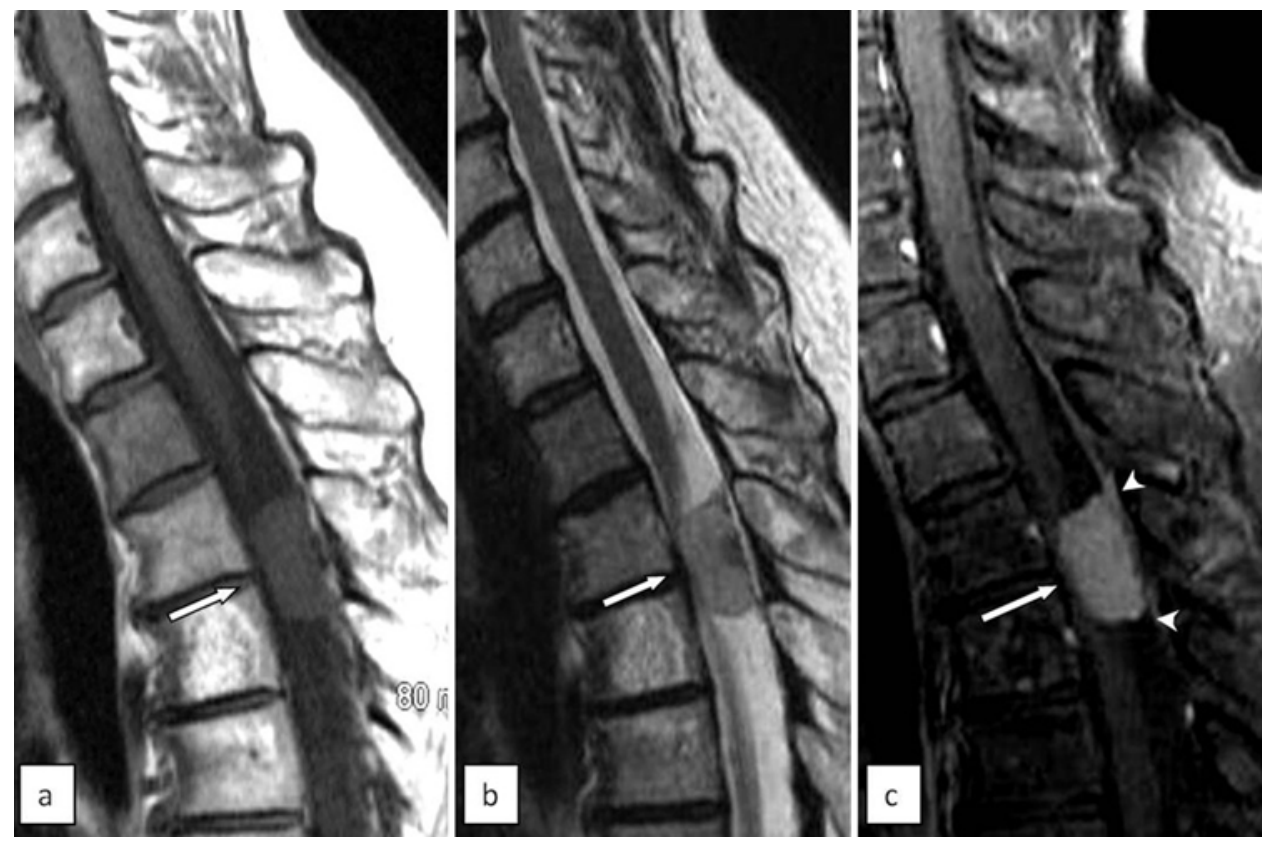

FIG. 12. Thoracic meningioma in a 56 -year-old female patient with progressive leg numbness and weakness. Sagittal T1-weighted (a) and T2-weighted (b) images demonstrate an iso- to hyperintense intradural lesion (white arrows) at the T-3 and T-4 levels with anterior displacement and compression of the spinal cord. The sagittal contrast-enhanced T1-weighted image (c) demonstrates a homogeneously enhancing tumor (white arrow) with dural tail sign (white arrowheads). 
risk of hemorrhage, allowing a more aggressive circumferential dissection and en bloc removal of the lesion. The indications, contraindications, and different embolization techniques are addressed below.

\section{Preoperative Embolization of Vascular Intraspinal Tumors}

For most vascular intraspinal tumors, en bloc microsurgical resection represents the definitive treatment. Nonetheless, vascular intraspinal tumors can be particularly difficult to operate on because of the hemorrhage that may occur during resection. Several reports have suggested that preoperative embolization of vascular intraspinal tumors is a safe procedure and that it can facilitate surgical resection while reducing the intraoperative blood loss and promoting an unimpeded view of the surgical field by decreasing the size of the lesion. ${ }^{12,14,44,52,72,77,94,103}$ Superselective catheterization of the supplying branches and transarterial embolization with various embolic agents are frequently used for this purpose (Figs. 13 and 14).

\section{Indications and Contraindications for Preoperative Embolization}

The use of endovascular therapy in the management of vascular intraspinal tumors has gradually evolved since the 1970s. In 2001, guidelines regarding head, neck, and brain tumor embolization were published by American Society of Interventional and Therapeutic Neuroradiology. The prerequisite for preoperative tumor embolization is a vascular mass. Eight criteria were set as indications for central nervous system tumor embolization: 1) to control surgically inaccessible arterial feeders, 2) to decrease surgical morbidity by reducing operative blood loss, 3) to shorten operative procedural time, 4) to increase the chances of complete resection, 5) to decrease the risk of damage to the adjacent normal tissue, 6) to relieve intractable pain, 7) to decrease tumor recurrence, and 8) to allow better visualization of the surgical field by causing tumor necrosis and shrinkage. 2,69 Many investigators have reported that preoperative endovascular embolization of vascular intraspinal tumors primarily facilitates resection and secondarily reduces the mortality and morbidity associated with resection, improving the clinical outcome. $9,12,32,38,48,52,77$

The presence of a radiculomedullary artery in close proximity to or from the same pedicle as the tumor-feeding arteries is considered a contraindication to embolization, as an inadvertent occlusion of spinal arteries may occur. ${ }^{9,71,90}$ In addition, arteriovenous shunting within the tumor, visualization of a radiculomedullary artery via intersegmental anastomoses, uncorrectable coagulopathy, and renal failure represent relative contraindications to intraspinal tumor embolization. ${ }^{72}$

\section{Types of Embolic Agents}

The embolic agents are classified into 3 categories: mechanical devices, particulate agents, and liquid agents. The liquid agents can be subdivided into 2 categories: sclerosants and adhesives (i.e., glues).

Mechanical devices, including balloons and coils, are permanent embolic agents and can be used to occlude large vessels. In the setting of tumor embolization, coils can be used to reduce blood flow in large vessels or in vessels with potentially dangerous collateral anastomoses in order to allow embolization with another substance. ${ }^{38,72}$ Unlike particles, they do not have the potential for peripheral dissemination. However, Berkefeld et al. ${ }^{10}$ found that coils were less efficacious for decreasing operative blood loss in spinal cord tumors compared with polyvinyl alcohol (PVA) particles with or without coils.

Particulate agents include PVA particles (Fig. 13), gelatin pledgets (Gelfoam), and autologous blood clot. Particulate agents are inert and water insoluble and can expand inside feeding vessels to promote occlusion. Compared with use of liquid agents, particle embolization is technically less challenging to perform. The particulate agents are radiolucent, and contrast solution is required to indirectly visualize the extent of embolization and for careful monitoring for contrast reflux along the microcatheter, signaling completed embolization. Embolization with particulate agents is temporary, as they often dissipate over time, thereby allowing recanalization of the vessels feeding the tumor. Because particulate agents have a high friction coefficient, they have a proclivity to clog catheters. ${ }^{38,48}$

Absorbable gelatin (Gelfoam) is a water-insoluble, sterile, hemostatic compressed sponge derived from purified porcine skin gelatin and capable of absorbing up to 45 times its weight of whole blood. ${ }^{26}$ In its powder form, which is no longer commercially available, the small size of the particles caused inadvertent small-vessel occlusion. ${ }^{10}$ In the sponge form, when cut into pieces of the desired size and injected though a sizable microcatheter using a contrast agent, it causes a temporary occlusion that is ideal for vascular ligation. It is degraded by enzymes, with subsequent recanalization starting between 7 and 10 days. Therefore, when absorbable gelatin is exclusively used for preoperative embolization, it is recommended that surgery be performed within 24-48 hours to prevent recanalization.

PVA particles are commonly used for distal embolization to occlude tumor vessels proximal to or at the capillary bed. ${ }^{39,48}$ The particle size ranges from 45 to $500 \mu \mathrm{m}$. PVA can incite an in situ inflammatory response that facilitates vessel occlusion. ${ }^{48}$ Embolization with PVA can degrade over time, leading to recanalization of feeding vessels. Better occlusion can be achieved by the deep penetration of small particles, but the risk of inadvertent embolization of normal vessels, in particular the sulco-commissural arteries, and leakage into the pulmonary tissue is higher than with large particles. In contrast, large particles have a lower risk of inadvertent embolization of normal vessels but do not penetrate the tumor tissue as deeply as small ones. Overly large particles can produce ineffective proximal occlusion and damage to the spinal cord..$^{2,48,77}$

$N$-butyl cyanoacrylate (NBCA) is a highly occlusive and permanent liquid embolization agent that can be injected through an extremely soft and flexible microcatheter, allowing a distal or superselective injection if desired (Fig. 5 ). Its radiographic visibility depends on the choice of concentration of the radiopaque material (ethiodized oil and/ or tantalum powder) in the solution prior to injection in the feeder (Fig. 14d). The NBCA or "glue" can be injected deep inside the tumor nidus and into specific casts to occlude the 

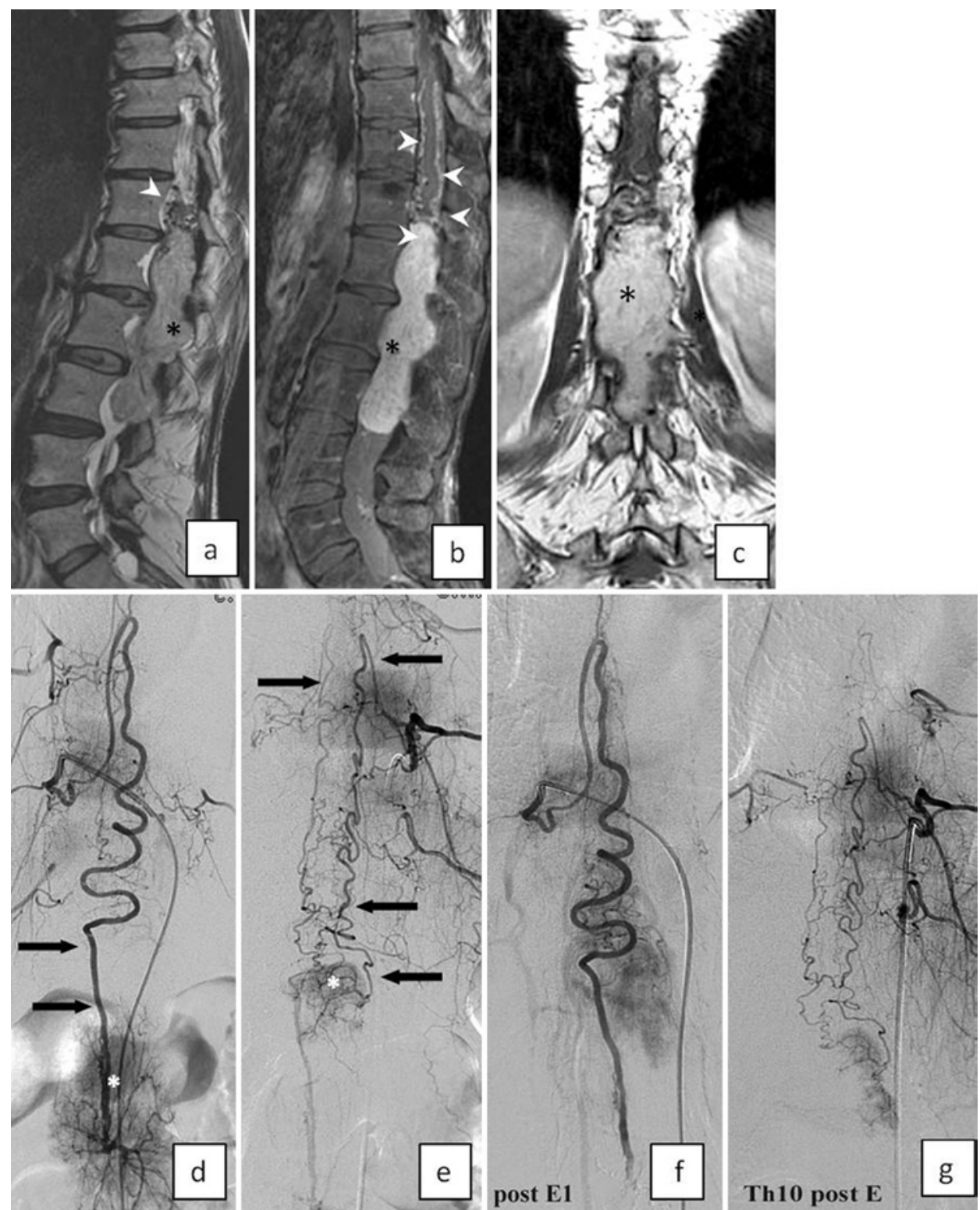

FIG. 13. Paraganglioma of the filum terminale in a 52-year-old female patient with bilateral papilledema and sciatica. Sagittal T2-weighted (a) and contrast-enhanced sagittal (b) and coronal (c) T1-weighted images show a large tumor (black asterisks) filling the spinal canal, with serpentine flow-voids/vessels ( $a$ and b, white arrowheads). Pre-embolization angiography of the right T-11 intercostal artery (d) reveals a vascular tumor (white asterisk) mainly vascularized by the artery of the filum terminale (black arrows) arising from the radiculomedullary artery of the lumbar enlargement. Left T-10 intercostal artery angiography (e) reveals the upper portion of the tumor blush (white asterisk) fed by the radiculopial artery (black arrows). A follow-up right T-11 intercostal artery angiograpm obtained after NBCA injection into the main feeder of the filum terminale below the basket via the anterior spinal axis (f) confirms devascularization of the lower compartment of the lesion. The upper compartment of the tumor was embolized with particles injected via the radiculopial artery from the left T-10 intercostal artery. A significant devascularization of the tumor was achieved (g). Panels b, d, and f are reproduced from Springer Neuroradiology 50:145-151, Embolization of intradural vascular spinal cord tumors, Rodesch et al., Fig. 2, with kind permission from Springer Science and Business Media.

feeding arteries (Figs. 5 and 14). NBCA-embolized arteries also have the added protection of permanent vessel occlusion. The disadvantages of NBCA include its relatively high cost, the prerequisite for experience and expertise in its handling, and the need for a new microcatheterization step with each branch vessel injection. ${ }^{38,48,99}$

Onyx is a liquid nonadhesive mixture of ethylene vinyl alcohol and metrizamide dissolved in dimethyl sulfoxide. Upon contact with blood, dimethyl sulfoxide dif- fuses rapidly, thereby forming an ethylene vinyl alcohol copolymer and thus mechanically occluding the feeding vessels. ${ }^{37,38,70,87,99}$ One retrospective case review involving patients with hypervascular extradural spinal tumors undergoing off-label transarterial Onyx embolization reported some advantages. ${ }^{36}$ Because of its diffusion properties, Onyx may occlude multiple arterial feeders in 1 injection. However, compared with NBCA, Onyx is less visible and offers a relatively higher risk of reflux that can cause in- 

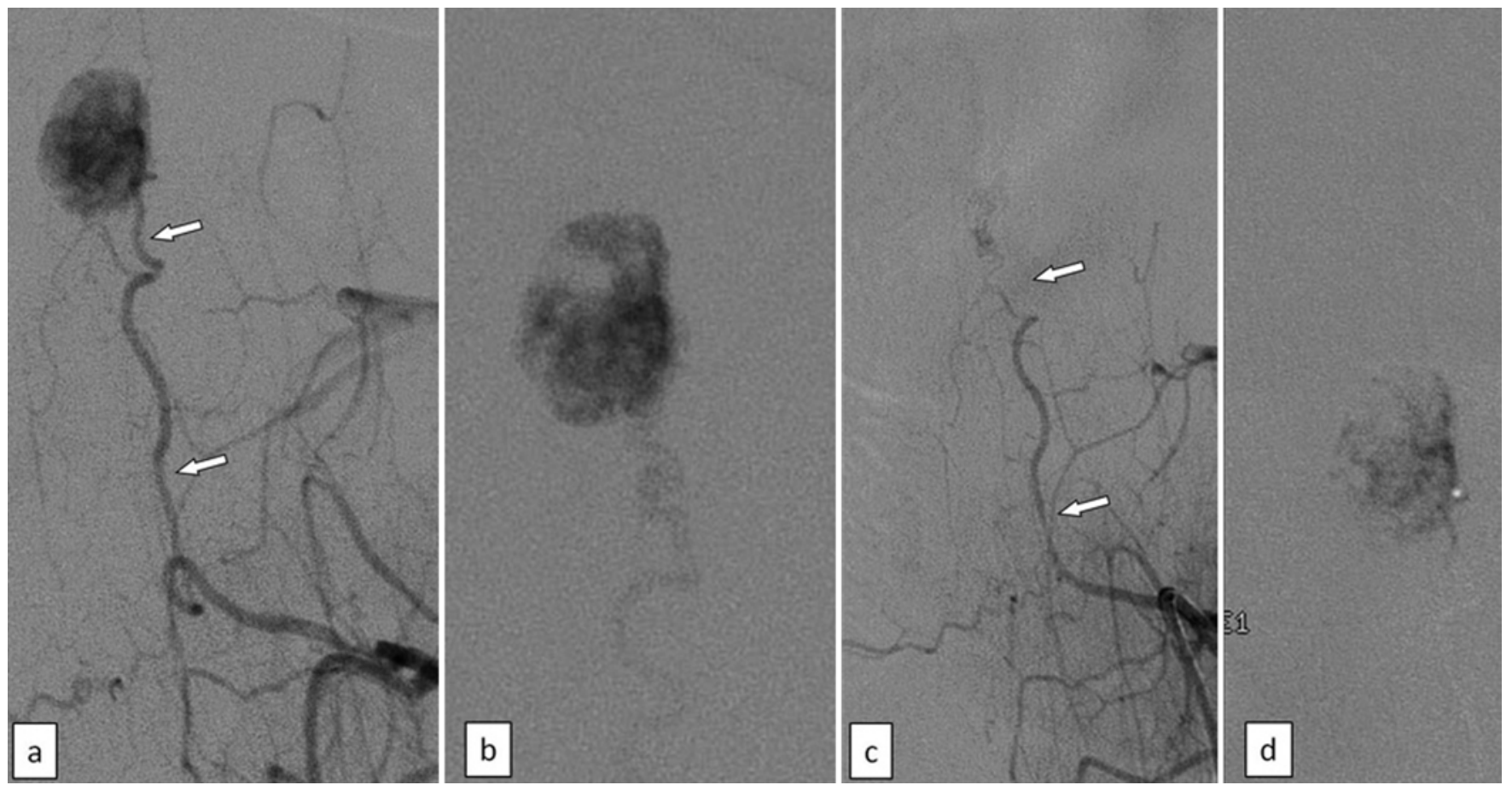

FIG. 14. Hemangioblastoma of the midthoracic spine in an asymptomatic 25 -year-old male patient with VHL disease and progressive tumor growth. Left T-8 intercostal arteriogram (a) shows a hypervascular intradural intramedullary tumor blush fed mainly by the posterior spinal/radiculopial artery (white arrows). Superselective microcatheter angiography through a 1.2-F microcatheter (b) reveals the detail of the vascular blush supplied by the left T-8 radiculopial feeder. Left T-8 intercostal angiography following selective intratumoral NBCA embolization (c) reveals significant devascularization of the tumor (white arrows). DSA (d) shows the cast of NBCA/ethiodized oil penetrating the tumor.

jury to the radiculomedullary arteries. In addition, due to the need of a relatively stiffer microcatheter for Onyx injection, superselective/distal catheterization may be unachievable. In addition, Onyx embolization requires prolonged fluoroscopy and procedure times. ${ }^{38,99}$

\section{Choice of Embolic Agent}

The choice of the optimal embolic agent depends on hemodynamic and angioarchitecture factors, on the desired properties of the embolic agent, and on the experience of the operator. Other considerations when choosing the embolic agent include the need for a permanent vascular occlusion, the feasibility for selective or superselective delivery of an embolic agent via a microcatheter, the safety of the reflux zone, the desired radio-opacity for visualization and pliability for ease of surgical handling, the immunological inactivity, and the lack of toxicity.

Particulate agents are the most frequently used embolic agents. The choice of the size of the particulate agents is made in relation to the size of the arteries to be occluded. In all cases, the particles used should be larger than the diameter of the normal vessels surrounding the tumor.

Recently, NBCA and Onyx have been adopted by more authors. Some ${ }^{38,48,77,78}$ consider NBCA their embolic agent choice since it offers a safer alternative to PVA if the injection can be mastered properly into the tumor's capillary bed. These authors described a surgical preference for NBCA embolization over PVA embolization because the tumor feeders that contain liquid adhesive were easily identified and dissected in surgery. If minor hemorrhage occurs around the cast of NBCA, some NBCA can be expressed from the end of the artery so that the vessel can hold bipolar coagulation or a clip. Gore et al. ${ }^{38}$ emphasized some of the advantages of using Onyx, including fewer arterial catheterizations and the possibility of less chance of catheter adherence.

\section{Endovascular Embolization Technique}

Embolization is usually conducted under general anesthesia to prevent the patient from moving during the procedure. Provocative testing using lidocaine or amytal are unreliable for the prediction of neurological deficits, because in the pre-embolization phase the blood flow is directed to the hypervascular tumor. Thus, careful angiographic analysis and clinical monitoring using somatosensory evoked potentials and electroencephalography are the main instruments to ensure the safety of the procedure..$^{10,48}$

The embolization technique includes the standard catheterization and infusion of the embolic agent into the feeding arteries via the catheter ${ }^{976}$ (Figs. 13 and 14). Safe embolization requires exclusive occlusion of the pathological vessels with optimal catheterization being performed as superselectively into the tumor feeder as possible. When superselective catheterization is difficult or impossible, "preferential" or "redirection" techniques, described as the embolization of normal vessels distal to the tumor feeder using gelatin pledgets or coils, may be used to ensure that the blood with the embolic agent flows toward the feeders. ${ }^{86}$ Coils are, for the most part, ineffective devices for direct tumor embolization because they occlude only the 
proximal vessels. ${ }^{44}$ Moreover, in cases of tumor recurrence requiring a second embolization, coils could block the vascular access needed to perform those interventions.

PVA has to be injected slowly to avoid dangerous reflux into normal branches. Wedged catheterization should be avoided as the injection of particulate agents carries the risk of rupture of the tumor or contamination of the intrinsic spinal cord vasculature. , $^{91,86}$ Onyx also should be injected slowly to avoid severe arterial injury from inflammation, endothelial necrosis, and vasospasm..$^{37,38}$ Injection of NBCA must be performed quickly and continuously to decrease the risks of gluing a microcatheter within the cast and of avulsing the feeding artery when the catheter is removed. ${ }^{38,48}$

The reported criteria for ending the endovascular session are the same as in particle embolization of a spinal arteriovenous malformation:11,12,77 1) appearance of anterior spinal artery branches of the same or larger caliber as the nidus to be embolized and 2) change in the flow pattern (i.e., slower filling of the nidus with faster filling of branches feeding normal structures). Repeated control angiography of potential feeding arteries at the completion of embolization is needed to fully assess the degree of devascularization achieved.,77 Short-duration, anesthesiologist-controlled apnea can be used during critical angiographic runs to reduce motion artifacts.

The timing of preoperative embolization is also an important technical consideration. Authors differ with respect to the optimal timing for surgery after embolization. ${ }^{21,31,39,46,48,87}$ Ozkan et al. ${ }^{72}$ suggested that surgery should ideally be performed within 24 hours of embolization to minimize the potential for tumor revascularization via collaterals. In routine practice, tumor embolization, when performed on an elective basis, is often planned 1-4 days before surgery. Other authors have recommended delayed surgery to permit a tumor to soften from massive necrosis and shrink..$^{21,87}$ Jüngling et al. ${ }^{45}$ reported that necrosis of meningioma after embolization began within 24 hours and might peak at 4 days, as seen by MRS. They suggested that surgery could be performed after this period. An observational study suggested that the greatest tumor softening was seen 7-9 days after embolization, facilitating surgical resection. ${ }^{46}$ Chun et al. ${ }^{21}$ reported that intraoperative blood loss was less for a group of patients who underwent delayed surgery (2-7 days after embolization) than for a group that underwent immediate surgery (within 24 hours after embolization). These different recommendations on the timing of surgery after embolization might depend on the embolic material used. An early surgical intervention can decrease the risk of tumor revascularization and collateral vessel formation. ${ }^{74}$ As the utilization of liquid agents greatly reduces risk of recanalization, some authors have advocated a delayed surgery to permit tumor necrosis that can facilitate resection. However, the optimal timing for surgery after embolization remains an area of debate and requires future clinical investigation.

\section{Procedure-Related Complications}

The most common complications after embolization are intratumoral hemorrhage and tumoral edema. ${ }^{24,32,77}$ Spinal cord ischemia due to inadvertent vessel embolization of unrecognized radiculomedullary arteries is a devastating possible complication. ${ }^{48,72}$ Other reported complications have included pain, and subarachnoid, peritumoral hemorrhage. ${ }^{32}$ A difficult microcatheter retrieval or breakage may occur during the procedure if NBCA or Onyx is used.42,43

Cornelius et al. ${ }^{24}$ summarized several studies on preoperative embolization and reported an embolization-related complication rate of $5.6 \%$ in patients with spinal hemangioblastomas. Shi et al. ${ }^{86}$ reported no complications after embolization in 18 cases of vascular spinal tumors. Other authors ${ }^{12,77}$ reported that no permanent complication occurred after embolization. For the practice of preoperative embolization in meningioma, the documented procedure-related complications for intracranial meningioma range from $2.5 \%$ to $6.5 \% .^{7,17,74}$ Cornelius et al. ${ }^{24}$ and Montano et al. ${ }^{65}$ evaluated the outcome of embolization for patients with hemangioblastomas in different locations and concluded that the outcome was favorable in patients with spinal cord hemangioblastomas, whereas those with a tumor in the cerebellum were at a relatively higher risk of embolizationrelated rupture. Acute tumor bleeding and death occurred in all of the latter cases. The authors speculated that the cerebellar hemangioblastomas had larger capillaries that allowed particles to occlude the venous sector, leading to their rupture. This hypothesis that the tumoral hemorrhage was due to obstruction of the venous outflow was reinforced by histological analysis. ${ }^{65}$ Given these pathophysiology changes,${ }^{87}$ some investigators ${ }^{47}$ suggested that graduated increases in particle size during the embolization might be helpful in diminishing the risk of hemorrhage by offering protection to the friable, distal tumor vessels.

Dissolution of clumped particulate agents and resolution of vasospasm may result in early recanalization and reperfusion of ischemic and leaky vascular beds, contributing to edema and swelling. ${ }^{87,101}$ Intravenous steroids could be administered to decrease the occurrence rate of tumor swelling. It is also believed that with the improvement of techniques and better understanding of the angiographic microanatomy, the complication occurrence rate could be effectively decreased.

Because of the deep penetration of liquid embolic agents, concerns have been raised that these might be associated with a relatively higher risk of complications such as spinal cord infarctions and inadvertent embolization of normal vessels. In a study by Kim et al., ${ }^{48}$ the inadvertent embolization rate in NBCA embolization was 3\%, which is consistent with the previously reported rate after particle embolization. Gore et al. ${ }^{38}$ reported no complication as a direct result of Onyx embolization. However, it should be noted that the potential risks of serious complications exist with the Onyx embolization procedure. ${ }^{70}$

\section{Summary}

A variety of imaging techniques are available for the diagnosis and the evaluation of vascular intraspinal tumors, among which MRI and angiography are the most helpful modalities. Common types of vascular intraspinal tumors, including hemangioblastoma, paraganglioma, and meningioma, have specific imaging features related to their hypervascularity. An accurate diagnosis with appropriate 
imaging modalities can facilitate the treatment strategies used. The preoperative embolization of vascular intraspinal tumors has been proven to facilitate the surgical procedure by decreasing blood loss, shortening the operation time, reducing the surgical morbidity, and increasing the chance of complete resection of the lesion. The optimal timing for surgery after embolization is still an area of debate. Complications can be prevented using a cautious surgical technique with careful analysis of the pre-embolization angiograms. This is essential to identify and protect the radiculomedullary arteries while aiming for complete resection.

\section{Acknowledgments}

We thank Dr. John Wolfe and Dr. Alfredo Walker, from the University of Ottawa, for assistance with the pathology figures used in this paper.

\section{References}

1. Abul-Kasim K, Thurnher MM, McKeever P, Sundgren PC: Intradural spinal tumors: current classification and MRI features. Neuroradiology 50:301-314, 2008

2. American Society of Interventional and Therapeutic Neuroradiology: Head, neck, and brain tumor embolization. AJNR Am J Neuroradiol 22 (8 Suppl):S14-S15, 2001

3. Arbelaez A, Castillo M, Armao D: Hemangioblastoma of the filum terminale: MR imaging. AJR Am J Roentgenol 173:857-858, 1999

4. Bagley CA, Gokaslan ZL: Cauda equina syndrome caused by primary and metastatic neoplasms. Neurosurg Focus 16(6):e3, 2004

5. Baker KB, Moran CJ, Wippold FJ II, Smirniotopoulos JG, Rodriguez FJ, Meyers SP, et al: MR imaging of spinal hemangioblastoma. AJR Am J Roentgenol 174:377-382, 2000

6. Balériaux DL: Spinal cord tumors. Eur Radiol 9:12521258,1999

7. Bendszus M, Monoranu CM, Schütz A, Nölte I, Vince GH, Solymosi L: Neurologic complications after particle embolization of intracranial meningiomas. AJNR Am J Neuroradiol 26: 1413-1419, 2005

8. Benes V III, Barsa P, Benes V Jr, Suchomel P: Prognostic factors in intramedullary astrocytomas: a literature review. Eur Spine J 18:1397-1422, 2009

9. Berenstein A, Lasjaunias P, terBrugge KG: Tumors of the spinal column and spinal cord, in Surgical Neuroangiography: Vol. 2: Clinical and Endovascular Treatment Aspects in Adults, ed 2. New York: SpringerVerlag, 2004, pp 873-911

10. Berkefeld J, Scale D, Kirchner J, Heinrich T, Kollath J: Hypervascular spinal tumors: influence of the embolization technique on perioperative hemorrhage. AJNR Am J Neuroradiol 20:757-763, 1999

11. Biondi A, Merland JJ, Reizine D, Aymard A, Hodes JE, Lecoz P, et al: Embolization with particles in thoracic intramedullary arteriovenous malformations: long-term angiographic and clinical results. Radiology 177:651-658, 1990

12. Biondi A, Ricciardi GK, Faillot T, Capelle L, Van Effenterre R, Chiras J: Hemangioblastomas of the lower spinal region: report of four cases with preoperative embolization and review of the literature. AJNR Am J Neuroradiol 26:936-945, 2005

13. Bloomer CW, Ackerman A, Bhatia RG: Imaging for spine tumors and new applications. Top Magn Reson Imaging 17:69-87, 2006

14. Breslau J, Eskridge JM: Preoperative embolization of spinal tumors. J Vasc Interv Radiol 6:871-875, 1995
15. Brisman JL, Borges LF, Ogilvy CS: Extramedullary hemangioblastoma of the conus medullaris. Acta Neurochir (Wien) 142:1059-1062, 2000

16. Browne TR, Adams RD, Roberson GH: Hemangioblastoma of the spinal cord. Review and report of five cases. Arch Neurol 33:435-441, 1976

17. Carli DFM, Sluzewski M, Beute GN, van Rooij WJ: Complications of particle embolization of meningiomas: frequency, risk factors, and outcome. AJNR Am J Neuroradiol 31:152-154, 2010

18. Caruso R, Wierzbicki V, Marrocco L, Salvati M: Paragangliomas of the cauda equina. Report of one case and review of the literature. J Exp Clin Cancer Res 25:269275, 2006

19. Chen CY, Chen PH, Yao MS, Chu JS, Chan WP: MRI of hemangioblastoma in the conus medullaris. Comput Med Imaging Graph 32:78-81, 2008

20. Chu BC, Terae S, Hida K, Furukawa M, Abe S, Miyasaka $\mathrm{K}$ : MR findings in spinal hemangioblastoma: correlation with symptoms and with angiographic and surgical findings. AJNR Am J Neuroradiol 22:206-217, 2001

21. Chun JY, McDermott MW, Lamborn KR, Wilson CB, Higashida R, Berger MS: Delayed surgical resection reduces intraoperative blood loss for embolized meningiomas. Neurosurgery 50:1231-1237, 2002

22. Citron N, Edgar MA, Sheehy J, Thomas DG: Intramedullary spinal cord tumours presenting as scoliosis. J Bone Joint Surg Br 66:513-517, 1984

23. Clark AJ, Lu DC, Richardson RM, Tihan T, Parsa AT, Chou D, et al: Surgical technique of temporary arterial occlusion in the operative management of spinal hemangioblastomas. World Neurosurg 74:200-205, 2010

24. Cornelius JF, Saint-Maurice JP, Bresson D, George B, Houdart E: Hemorrhage after particle embolization of hemangioblastomas: comparison of outcomes in spinal and cerebellar lesions. J Neurosurg 106:994-998, 2007

25. Couch V, Lindor NM, Karnes PS, Michels VV: von HippelLindau disease. Mayo Clin Proc 75:265-272, 2000

26. Council on Pharmacy and Chemistry: New and nonofficial remedies. Absorbable gelatin sponge. JAMA 135:921, 1947

27. da Costa LB Jr, de Andrade A, Braga BP, Ribeiro CA: Cauda equina hemangioblastoma: case report. Arq Neuropsiquiatr 61 (2B): 456-458, 2003

28. De Verdelhan O, Haegelen C, Carsin-Nicol B, Riffaud L, Amlashi SFA, Brassier G, et al: MR imaging features of spinal schwannomas and meningiomas. J Neuroradiol 32:42-49, 2005

29. Deng X, Wang K, Wu L, Yang C, Yang T, Zhao L, et al: Intraspinal hemangioblastomas: analysis of 92 cases in a single institution: clinical article. J Neurosurg Spine 21:260-269, 2014

30. Ducreux D, Fillard P, Facon D, Ozanne A, Lepeintre JF, Renoux J, et al: Diffusion tensor magnetic resonance imaging and fiber tracking in spinal cord lesions: current and future indications. Neuroimaging Clin N Am 17:137-147, 2007

31. Engelhard HH: Progress in the diagnosis and treatment of patients with meningiomas. Part I: diagnostic imaging, preoperative embolization. Surg Neurol 55:89-101, 2001

32. Eskridge JM, McAuliffe W, Harris B, Kim DK, Scott J, Winn HR: Preoperative endovascular embolization of craniospinal hemangioblastomas. AJNR Am J Neuroradiol 17:525-531, 1996

33. Faro SH, Turtz AR, Koenigsberg RA, Mohamed FB, Chen CY, Stein H: Paraganglioma of the cauda equina with associated intramedullary cyst: MR findings. AJNR Am J Neuroradiol 18:1588-1590, 1997

34. Friedrich H, Hänsel-Friedrich G, Zeumer H: Intramedullary vascular lesions in the high cervical region: transoral and 
dorsal surgical approach. Two case reports. Neurosurg Rev 13:65-71, 1990

35. Gezen F, Kahraman S, Çanakci Z, Bedük A: Review of 36 cases of spinal cord meningioma. Spine (Phila Pa 1976) 25:727-731, 2000

36. Ghobrial GM, Chalouhi N, Harrop J, Dalyai RT, Tjoumakaris S, Gonzalez LF, et al: Preoperative spinal tumor embolization: an institutional experience with Onyx. Clin Neurol Neurosurg 115:2457-2463, 2013

37. Gobin YP, Murayama Y, Milanese K, Chow K, Gonzalez NR, Duckwiler GR: Head and neck hypervascular lesions: embolization with ethylene vinyl alcohol copolymerlaboratory evaluation in swine and clinical evaluation in humans. Radiology 221:309-317, 2001

38. Gore P, Theodore N, Brasiliense L, Kim LJ, Garrett M, Nakaji P, et al: The utility of onyx for preoperative embolization of cranial and spinal tumors. Neurosurgery 62: 1204-1212, 2008

39. Gottfried ON, Schmidt MH, Stevens EA: Embolization of sacral tumors. Neurosurg Focus 15(2):E4, 2003

40. Hunt WE: Grading of patients with aneurysms. J Neurosurg 47:133, 1977 (Letter)

41. Ibrahim GM, Hawkins C, Fehlings MG: The diagnosis of spinal tumors: established and emerging methods. Expert Opin Med Diagn 6:95-108, 2012

42. Inci S, Ozcan OE, Benli K, Saatçi I: Microsurgical removal of a free segment of microcatheter in the anterior circulation as a complication of embolization. Surg Neurol 46:562567,1996

43. Ito M, Sonokawa T, Mishina H, Iizuka Y, Sato K: Disrupted and migrated microcatheter in the vertebrobasilar artery system in endovascular embolization of cerebellar AVM: failure of endovascular and microneurosurgical retrieval. J Clin Neurosci 5 Suppl:49-53, 1998

44. Jones K, Meyers P, Gobin P, Liu AH: Embolization of spinal tumors. Oper Tech Neurosurg 6:156-162, 2003

45. Jüngling FD, Wakhloo AK, Hennig J: In-vivo proton spectroscopy of meningioma after preoperative embolization. Magn Reson Med 30:155-160, 1993

46. Kai Y, Hamada J, Morioka M, Yano S, Todaka T, Ushio $\mathrm{Y}$ : Appropriate interval between embolization and surgery in patients with meningioma. AJNR Am J Neuroradiol 23:139-142, 2002

47. Kallmes DF, Evans AJ, Kaptain GJ, Mathis JM, Jensen ME, Jane JA, et al: Hemorrhagic complications in embolization of a meningioma: case report and review of the literature. Neuroradiology 39:877-880, 1997

48. Kim LJ, Albuquerque FC, Aziz-Sultan A, Spetzler RF, McDougall CG: Low morbidity associated with use of n-butyl cyanoacrylate liquid adhesive for preoperative transarterial embolization of central nervous system tumors. Neurosurgery 59:98-104, 2006

49. Kliewer KE, Wen DR, Cancilla PA, Cochran AJ: Paragangliomas: assessment of prognosis by histologic, immunohistochemical, and ultrastructural techniques. Hum Pathol 20:29-39, 1989

50. Koeller KK, Rosenblum RS, Morrison AL: Neoplasms of the spinal cord and filum terminale: radiologic-pathologic correlation. Radiographics 20:1721-1749, 2000

51. Koizumi S, Sakai N, Kawaji H, Takehara Y, Yamashita S, Sakahara H, et al: Pseudo-continuous arterial spin labeling reflects vascular density and differentiates angiomatous meningiomas from non-angiomatous meningiomas. $\mathbf{J}$ Neurooncol 121:549-556, 2015

52. Lee DK, Choe WJ, Chung CK, Kim HJ: Spinal cord hemangioblastoma: surgical strategy and clinical outcome. J Neurooncol 61:27-34, 2003

53. Lee KY, Oh YW, Noh HJ, Lee YJ, Yong HS, Kang EY, et al: Extraadrenal paragangliomas of the body: imaging features. AJR Am J Roentgenol 187:492-504, 2006
54. Lerman RI, Kaplan ES, Daman L: Ganglioneuromaparaganglioma of the intradural filum terminale. Case report. J Neurosurg 36:652-658, 1972

55. Lonser RR, Oldfield EH: Microsurgical resection of spinal cord hemangioblastomas. Neurosurgery 57 (4 Suppl):372376,2005

56. Louis DN, Ohgaki H, Wiestler OD, Cavenee WK, Burger PC, Jouvet A, et al: The 2007 WHO classification of tumours of the central nervous system. Acta Neuropathol 114:97-109, 2007

57. Lowe GM: Magnetic resonance imaging of intramedullary spinal cord tumors. J Neurooncol 47:195-210, 2000

58. Maiuri F, De Caro MLDB, de Divitiis O, Vergara P, Mariniello G: Spinal meningiomas: age-related features. Clin Neurol Neurosurg 113:34-38, 2011

59. Manzano G, Green BA, Vanni S, Levi AD: Contemporary management of adult intramedullary spinal tumors-pathology and neurological outcomes related to surgical resection. Spinal Cord 46:540-546, 2008

60. Mechtler L: Neuroimaging in neuro-oncology. Neurol Clin 27:171-201, ix, 2009

61. Mechtler LL, Nandigam K: Spinal cord tumors: new views and future directions. Neurol Clin 31:241-268, 2013

62. Miliaras GC, Kyritsis AP, Polyzoidis KS: Cauda equina paraganglioma: a review. J Neurooncol 65:177-190, 2003

63. Miller CA, Torack RM: Secretory ependymoma of the filum terminale. Acta Neuropathol 15:240-250, 1970

64. Mishra T, Goel NA, Goel AH: Primary paraganglioma of the spine: A clinicopathological study of eight cases. J Craniovertebr Junction Spine 5:20-24, 2014

65. Montano N, Doglietto F, Pedicelli A, Albanese A, Lauretti L, Pallini R, et al: Embolization of hemangioblastomas. J Neurosurg 108: 1063-1065, 2008

66. Moran CA, Rush W, Mena H: Primary spinal paragangliomas: a clinicopathological and immunohistochemical study of 30 cases. Histopathology 31:167-173, 1997

67. Morota N, Deletis V, Constantini S, Kofler M, Cohen H, Epstein FJ: The role of motor evoked potentials during surgery for intramedullary spinal cord tumors. Neurosurgery 41:1327-1336, 1997

68. Murota T, Symon L: Surgical management of hemangioblastoma of the spinal cord: a report of 18 cases. Neurosurgery 25:699-708, 1989

69. Nair S, Gobin YP, Leng LZ, Marcus JD, Bilsky M, Laufer I, et al: Preoperative embolization of hypervascular thoracic, lumbar, and sacral spinal column tumors: technique and outcomes from a single center. Interv Neuroradiol 19:377385,2013

70. Lv X, Jiang C, Li Y, Wu Z, Wu Z: Results and complications of transarterial embolization of intracranial dural arteriovenous fistulas using Onyx-18. J Neurosurg 109:10831090, 2008

71. O'Reilly GV, Kleefield J, Klein LA, Blume HW, Dubuisson D, Cosgrove GR: Embolization of solitary spinal metastases from renal cell carcinoma: alternative therapy for spinal cord or nerve root compression. Surg Neurol 31:268-271, 1989

72. Ozkan E, Gupta S: Embolization of spinal tumors: vascular anatomy, indications, and technique. Tech Vasc Interv Radiol 14:129-140, 2011

73. Pattany PM, Saraf-Lavi E, Bowen BC: MR angiography of the spine and spinal cord. Top Magn Reson Imaging 14:444-460, 2003

74. Probst EN, Grzyska U, Westphal M, Zeumer H: Preoperative embolization of intracranial meningiomas with a fibrin glue preparation. AJNR Am J Neuroradiol 20:1695-1702, 1999

75. Rao AB, Koeller KK, Adair CF: From the archives of the AFIP. Paragangliomas of the head and neck: radiologicpathologic correlation. Radiographics 19:1605-1632, 1999 
76. Rodesch G, Lasjaunias P: Spinal cord arteriovenous shunts: from imaging to management. Eur J Radiol 46:221-232, 2003

77. Rodesch G, Gaillard S, Loiseau H, Brotchi J: Embolization of intradural vascular spinal cord tumors: report of five cases and review of the literature. Neuroradiology 50:145151,2008

78. Rodesch G, Hurth M, Alvarez H, David P, Tadie M, Lasjaunias P: Embolization of spinal cord arteriovenous shunts: morphological and clinical follow-up and results - review of 69 consecutive cases. Neurosurgery 53:40-50, 2003

79. Roux FX, Nataf F, Pinaudeau M, Borne G, Devaux B, Meder JF: Intraspinal meningiomas: review of 54 cases with discussion of poor prognosis factors and modern therapeutic management. Surg Neurol 46:458-464, 1996

80. Sala F, Bricolo A, Faccioli F, Lanteri P, Gerosa M: Surgery for intramedullary spinal cord tumors: the role of intraoperative (neurophysiological) monitoring. Eur Spine J 16 Suppl 2:S130-S139, 2007

81. Salehpour F, Zeinali A, Vahedi P, Halimi M: A rare case of intramedullary cervical spinal cord meningioma and review of the literature. Spinal Cord 46:648-650, 2008

82. Salpietro FM, Alafaci C, Lucerna S, Iacopino DG, Tomasello F: Do spinal meningiomas penetrate the pial layer? Correlation between magnetic resonance imaging and microsurgical findings and intracranial tumor interfaces. Neurosurgery 41:254-258, 1997

83. Saraceni C, Harrop JS: Spinal meningioma: chronicles of contemporary neurosurgical diagnosis and management. Clin Neurol Neurosurg 111:221-226, 2009

84. Sayagués JM, Tabernero MD, Maíllo A, Trelles O, Espinosa $\mathrm{AB}$, Sarasquete ME, et al: Microarray-based analysis of spinal versus intracranial meningiomas: different clinical, biological, and genetic characteristics associated with distinct patterns of gene expression. J Neuropathol Exp Neurol 65:445-454, 2006

85. Sciubba DM, Mavinkurve GG, Gailloud P, Garonzik IM, Recinos PF, McGirt MJ, et al: Preoperative imaging of cervical spine hemangioblastomas using three-dimensional fusion digital subtraction angiography. Report of two cases. J Neurosurg Spine 5:96-100, 2006

86. Shi HB, Suh DC, Lee HK, Lim SM, Kim DH, Choi CG, et al: Preoperative transarterial embolization of spinal tumor: embolization techniques and results. AJNR Am J Neuroradiol 20:2009-2015, 1999

87. Shi Z, Feng L, Jiang X, Huang Q: Therapeutic embolization of meningiomas with Onyx for delayed surgical resection. Surg Neurol 70:478-481, 2008

88. Shin JY, Lee SM, Hwang MY, Sohn CH, Suh SJ: MR findings of the spinal paraganglioma: report of three cases. J Korean Med Sci 16:522-526, 2001

89. Smirniotopoulos JG, Murphy FM: The phakomatoses. AJNR Am J Neuroradiol 13:725-746, 1992

90. Smith TP, Gray L, Weinstein JN, Richardson WJ, Payne CS: Preoperative transarterial embolization of spinal column neoplasms. J Vasc Interv Radiol 6:863-869, 1995

91. Solero CL, Fornari M, Giombini S, Lasio G, Oliveri G, Cimino C, et al: Spinal meningiomas: review of 174 operated cases. Neurosurgery 25:153-160, 1989

92. Soubeyrand M, Court C, Fadel E, Vincent-Mansour C, Mascard E, Vanel D, et al: Preoperative imaging study of the spinal cord vascularization: interest and limits in spine resection for primary tumors. Eur J Radiol 77:26-33, 2011

93. Sundgren P, Annertz M, Englund E, Strömblad LG, Holtås $\mathrm{S}$ : Paragangliomas of the spinal canal. Neuroradiology 41:788-794, 1999

94. Thiex R, Harris MB, Sides C, Bono CM, Frerichs KU: The role of preoperative transarterial embolization in spinal tumors. A large single-center experience. Spine J 13:141149,2013
95. Toyoda H, Seki M, Nakamura H, Inoue Y, Yamano Y, Takaoka K: Intradural extramedullary hemangioblastoma differentiated by MR images in the cervical spine: a case report and review of the literature. J Spinal Disord Tech 17:343-347, 2004

96. Traul DE, Shaffrey ME, Schiff D: Part I: spinal-cord neoplasms-intradural neoplasms. Lancet Oncol 8:35-45, 2007

97. Van Goethem JWM, van den Hauwe L, Özsarlak O, De Schepper AMA, Parizel PM: Spinal tumors. Eur J Radiol 50:159-176, 2004

98. Van Velthoven V, Reinacher PC, Klisch J, Neumann HPH, Gläsker S, Bristol RE, et al: Treatment of intramedullary hemangioblastomas, with special attention to von HippelLindau disease. Neurosurgery 53:1306-1314, 2003

99. Velat GJ, Reavey-Cantwell JF, Sistrom C, Smullen D, Fautheree GL, Whiting J, et al.: Comparison of N-butyl cyanoacrylate and onyx for the embolization of intracranial arteriovenous malformations: analysis of fluoroscopy and procedure times. Neurosurgery $63(1 \mathrm{Suppl})$ : ONS73ONS80, 2008

100. Vertinsky AT, Krasnokutsky MV, Augustin M, Bammer R: Cutting-edge imaging of the spine. Neuroimaging Clin $\mathbf{N}$ Am 17:117-136, 2007

101. Wakhloo AK, Juengling FD, Van Velthoven V, Schumacher M, Hennig J, Schwechheimer K: Extended preoperative polyvinyl alcohol microembolization of intracranial meningiomas: assessment of two embolization techniques. AJNR Am J Neuroradiol 14:571-582, 1993

102. Wein S, Gaillard F: Intradural spinal tumours and their mimics: a review of radiographic features. Postgrad Med J 89:457-469, 2013

103. Wilson MA, Cooke DL, Ghodke B, Mirza SK: Retrospective analysis of preoperative embolization of spinal tumors. AJNR Am J Neuroradiol 31:656-660, 2010

104. Wu L, Yang T, Yang C, Deng X, Fang J, Xu Y: Surgical treatment of intraspinal angiomatous meningiomas from a single center. Neurol Med Chir (Tokyo) 55:328-335, 2015

105. Xu QW, Bao WM, Mao RL, Yang GY: Magnetic resonance imaging and microsurgical treatment of intramedullary hemangioblastoma of the spinal cord. Neurosurgery 35:671-676, 1994

106. Yang SY, Jin YJ, Park SH, Jahng TA, Kim HJ, Chung CK: Paragangliomas in the cauda equina region: clinicopathoradiologic findings in four cases. J Neurooncol 72:49-55, 2005

107. Yaşargil MG, Antic J, Laciga R, de Preux J, Fideler RW, Boone SC: The microsurgical removal of intramedullary spinal hemangioblastomas. Report of twelve cases and a review of the literature. Surg Neurol (3):141-148, 1976

108. Zozulya YP, Slin'ko EI, Al-Qashqish II: Spinal arteriovenous malformations: new classification and surgical treatment. Neurosurg Focus 20(5):E7, 2006

\section{Author Contributions}

Conception and design: dos Santos, Zhang, Tampieri. Acquisition of data: dos Santos, Zhang, Agid, Rodesch, Tampieri, terBrugge. Analysis and interpretation of data: dos Santos, Zhang, Glikstein. Drafting the article: dos Santos, Zhang, Ghinda, Glikstein, Agid. Critically revising the article: all authors. Reviewed submitted version of manuscript: all authors. Approved the final version of the manuscript on behalf of all authors: dos Santos. Administrative/technical/material support: dos Santos. Study supervision: dos Santos.

\section{Correspondence}

Marlise P. dos Santos, Department of Medical Imaging, The Ottawa Hospital, University of Ottawa, Mailbox 232, Office\# 01-1-10-A, 1053 Carling Ave., Ottawa, ON K1Y 4E9, Canada. email: msantos@ohri.ca. 